\title{
A MULTISITE CASE STUDY OF EARLY ALERT IMPLEMENTION TO ADOPTION AT THE UNIVERSITY OF MISSOURI SYSTEM
}

\author{
A Dissertation \\ presented to \\ the Faculty of the Graduate School \\ at the University of Missouri-Columbia \\ In Partial Fulfillment \\ of the Requirements for the Degree \\ Doctor of Educational Leadership and Policy Analysis \\ by \\ CHRISTINA (TINA) JEAN BALSER \\ Dr. Casandra Harper Morris, Dissertation Supervisor \\ MAY 2018
}


The undersigned, appointed by the dean of the Graduate School, have examined the dissertation entitled

\section{A MULTISITE CASE STUDY OF EARLY ALERT IMPLEMENTION TO ADOPTION AT THE UNIVERSITY OF MISSOURI SYSTEM}

presented by Christina (Tina) Jean Balser, a candidate for the degree of doctor of educational leadership and policy analysis, and hereby certify that, in their opinion, it is worthy of acceptance.

Professor Casandra Harper Morris

Professor Jennifer Fellabaum-Toston

Professor Isa Jahnke

Professor Gabrielle Malfatti 


\section{DEDICATION}

I am eternally grateful for the love and support of my family throughout my educational journey. My husband Nick has supported me being in graduate school for over seven years, more than half of our marriage, as I pursued both master's and doctoral degrees at the University of Missouri. With the challenges of owning a business, excelling in a new role at the university, school obligations, the gift of motherhood, and homeownership all happened during my coursework. Two beautiful children later, we have finally arrived. As I tried to balance work, school, and family obligations, he has been the one to give me grace, support and strength to embrace the challenges of classwork, comprehensive exams, and the dissertation process. Thank you for being an amazing husband and father every step of the way. Thank you for functioning as a single parent on the many days when I was gone to class or busy working on projects. Most of all, thank you for making me laugh every day in spite of all life's challenges. I love you.

My two kids, Izzy and Max, I love you both so much and I am thankful that you will never have to remember the time that mommy was in school. I hope you know that I always wanted to be playing with you rather than being away from you. This was a sacrifice for our family and I know that looking back our family with be better because of it. I hope that growing up you see me as a positive role model and in spite of everything else if you work hard enough your dreams will come true.. You can overcome anything if you put your mind to it and if you are willing to do the work.

Finally, my family and close friends that have provided support to pursue educational endeavors and professional advancement. After all of the heart breaks personally with the loss of loved ones, like my mom, who would have ever thought that this was possible? Thank you to my family for never letting me think that because of the roadblocks that this was ever out of reach. I will continue to make you proud. 


\section{ACKNOWLEDGEMENTS}

I am grateful to the four members of my committee for their support, encouragement, and mentorship throughout my doctoral career. On the first day at EdD orientation there were four things I was told to do if I wanted to be successful; read, write, think and talk. While so simple in nature those words were complex at times and gave me comfort when life got in the way. I am so thankful for all of the faculty that supported me in the doctoral journey. My current advisor and committee chair, Dr. Casandra Harper-Morris, provided invaluable guidance with conceptual challenges and support in developing my scholarly writing. Thank you for your guidance in my coursework and throughout the dissertation process. I am grateful for all of the time that you have spent coaching and mentoring me. To my external reviewer, Brenda Selman for time and input to make sure that I was providing an accurate and fair picture of the setting of my study. To Dr. Jim Spain who believed in me to carry out a new campus initiative and supported my research interest of this topic. My colleagues and friends in Cohort 9. Thank you for all of your encouragement and strength every step of the way. 


\section{TABLE OF CONTENTS}

ACKNOWLEDGEMENTS ................................................................................. ii

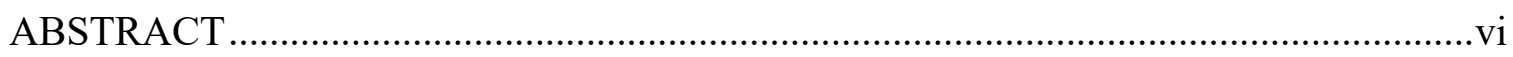

1. INTRODUCTION TO DISSERTATION- IN- PRACTICE ................................... 1

Statement of the Problem

Purpose of the Study

Research Questions

Conceptual Framework

Design of the Study

Setting and Participants

Data Collection Tools

Data Analysis

Ethical Considerations

Limitations, Assumptions, and Design Controls

Definition of Key Terms

Significance of the Study

Summary

2. PRACTITIONER SETTING FOR THE STUDY

History of the Organization

University of Missouri

University of Missouri-Kansas City

University of Missouri-St. Louis

Missouri University of Science and Technology 
Organizational Analysis

Structural Analysis

Political Analysis

Leadership Analysis

Implications for Research in the Practitioner Setting

Summary

3. SCHOLARLY REVIEW FOR THE STUDY

Leavitt's Diamond Model

Socio-Technical Systems

Readiness for Technology Adoption

4. CONTRIBUTION TO PRACTICE

UM System Executive Summary

5. CONTRIBUTION TO SCHOLARSHIP

Submission-Ready Journal Article: A University System Approach to Early Alert Implementation - A Multisite Case Study of How People, Task and Technology Influence Implementation and Adoption.

6. SCHOLARLY PRACTITIONER REFLECTION

Dissertation Influencing Education Leadership

Leadership Theory

My Mental Model

Equitable Problem Solving and Decision Making

Educator as a Leader

Leader as a Change Agent

Dissertation Influencing Scholarship 
Conclusion

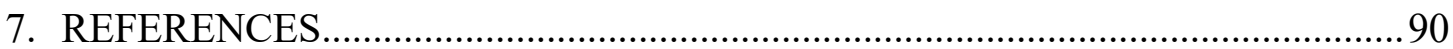

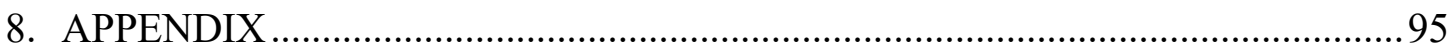

Recruitment Email

Consent Form

Interview Questions

Focus Group Questions

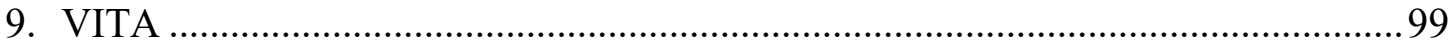




\title{
A MULTISITE CASE STUDY OF EARLY ALERT IMPLEMENTION TO ADOPTION AT THE UNIVERSITY OF MISSOURI SYSTEM
}

\author{
Christina (Tina) Jean Balser \\ Dr. Casandra Harper Morris, Dissertation Supervisor
}

\begin{abstract}
This multisite case study of academic early alert warning system implementation explored the relationship between leadership, users (faculty and staff), technology, and the organization when implementing a campus wide early alert program facilitated by new technology at a university system in the Midwest. Early alert technology allows faculty and staff to raise academic concerns and outreach to students during the semester. The findings suggested that technology, people, task and structure were core components impacting implementation and adoption of tools. The findings also suggested that clear expectations from leadership, alignment of tasks within job duties, clearly defined processes, resources to support training, and data outcomes are essential to early alert adoption.
\end{abstract}




\section{SECTION ONE:}

\section{INTRODUCTION TO DISSERTATION- IN-PRACTICE}

In 2012, the Missouri's performance funding bill spurred many Missouri higher education institutions to evaluate current programs and planning to align institutional resources with the new funding appropriations set by Senate Bill 492 (2014). The Missouri general assembly's intent was to appropriate state funding is beginning in fiscal year 2016. The state of Missouri chose five pillars to fund two-year and four-year institutions based on performance of 1) student success and progress, 2) degree attainment, 3) quality of student learning, 4) financial responsibility and efficiency, and 5) a specific institutional benchmark. A sixth pillar of 6) student job placement was added, but no funding would be allocated until further measures and discussion in fiscal year 2018. Each of the current performance pillars represent $20 \%$ of funding available that each school will be measured against and obtain additional funding for their institution. If an institution meets all five pillars they will receive $100 \%$ of funding available from the increase of initial state allocations of core funding (Missouri Department of Higher Education, 2012).

The University of Missouri System responded to performance funding by developing a Comprehensive Retention Initiative (CRI). The CRI committee coordinated a strategic planning process and identified many objectives, one of which was to implement a menu of student success technologies to support retention and graduation. This new initiative was a top down approach from the UM System to each of the four campuses to support retention and graduation success rates. One of the technology requirements was to support a campus wide academic early alert system at all four UM system campuses. The early alert system aims to support identification of students academically at-risk and supporting outreach efforts to support student success. The UM system purchased Starfish, an academic early alert system, in spring 2014. The 
Starfish system has gone through a variety of implementation phases at each of the UM campuses: the University of Missouri, University of Missouri-St. Louis, University of MissouriKansas City, and Missouri Science and Technology. Each campus had its own implementation plan for the design of the early alert technology, faculty onboarding, outreach and intervention plans, and student communications. Each campus identified core leadership and users to support the implementation and adoption.

According to Greenfield, Keup, and Gardner (2013) early alert warning systems (EAWS) are evolving in higher education. Campuses from around the United States are adopting new practices supported by technology to reach out to students about academic, financial, social, and health concerns raised by a staff or faculty member that can impact student persistence (Greenfield et al., 2013). Students come to college with varying levels of academic preparation that may contribute to their academic success (Bean, 1990). There are academic, motivational, psychosocial and financial factors that can be proactively identified early on to influence students' persistence (Barefoot, 2004). The ability to systematically identify students who are experiencing academic difficulty provides an opportunity for institutions to intervene. (Cuseo, 2006; Greenfield et al. 2013; Tampke 2009). Institutions in the past did not have a way to respond early in the semester to student behavior that contributed to their academic success. However, with these new early alert systems the current practice can be changed to raise concerns and outreach to students during the semester to with the goal to positively affect student, faculty, and university level behavior toward improved student success. This reactive practice to raise academic concerns and outreach to students during the semester is known as early alert. While the early alert process itself is proactive to address concerns prior to the end of the term, it is truly a reactive practice because users are reacting to student behaviors during the 
term. A proactive retention process would occur prior to the start of the term using predictive data sets to identify students that are at risk before ever stepping into a classroom.

Following the studies by Tampke (2009), Cuseo (2006), and Simons (2011), early alert process have evolved in many ways across higher education institutions. They started a traditional mid-term check paper based process, where a faculty would fill out an internal form, submit to the dean's office and it would take weeks to get to a dean to reach out and meet with a student (Gardener et al., 2013). In addition, the outreach in earlier years was not designed as service-oriented at all; it was like coming into the principal's office (Tampke, 2009). Recent studies demonstrate that in order for early alert to be successful, the following conditions must be present: a) faculty and academic support areas should participate (Greenfield et al., 2013, Tampke, 2009), b) students should feel that they can approach the office or person that is reaching out (Tampke, 2009), c) instructors should engage in early alert as a social practice, they may be introduced to the practice and new technology for the first time. Campuses are looking at these types of systems as a strategic solution and investing resources into new tools, but it is critical that there is support of all users (students, faculty, staff and leadership) involved in the process.

Early alert systems are defined as "a systematic method of recording and communicating student behaviors that contribute to student attrition that can aid in student retention efforts" (Tampke, 2012, p. 524). Retention of students is a constant topic of conversation and concern at many universities (Tampke, 2009). While the early alert technology is new to higher education, the process of identifying students that may be experiencing academic difficulty is not a new, but how concerns are reported may change with new technology. The early alert technology enhances a real-time reactive capability during the semester to allow instructors to raise flags and 
academic support offices to identify students who are experiencing academic difficulty and proactively reach out (Tampke, 2012). Students experiencing academic difficulty can benefit from effective interventions that then improve their chances of being retained (Tampke, 2009). More specifically, "students who do not experience academic success during their first semester of attendance will be less likely to be retained" (Greenfield et al., 2013, p. 179). While an early alert system is known to have a positive impact on student success and retention (Tampke, 2009), there are several variables that play a role in why there are varying levels of user adoption of these early alert systems, including the relationship between technology, individuals, and the organization (Leavitt,1964).

Leavitt (1964) argues that when approaching change through the use of technology, organizations must understand "that human acceptance is the real carrier of change and that emotional human resistance is the real road block" (p. 62). Clarke (2006) discusses that "systems" are beyond the technology and software. That technology is one area, but the system as a whole must take into account organizational, interactional, and the psychological context in which system are used. Technology approaches may fail because the human needs are ignored and there is a greater focus only on the technology resulting in costly and negative directions (Grudin, 1988; Leavitt, 1964).

\section{Statement of the Problem}

There is an adoption challenge regarding how faculty, staff, and students engage with a new early alert technology and supporting processes. In addition, there is a design challenge to align work processes with technology from a socialization and organizational view. Faculty raising flags and intervention mechanisms in place provided by staff or peer support are central to early alert implementation (Tampke, 2012). Regardless of institutional complexity, critical 
partners for EAWS are instructors, academic advisors, counselors, peer mentors, financial aid advisors, residential life staff, and tutors (Greenfield et al., 2013). A primary function of early alert is faculty participation to identify students that may be experiencing academic difficulty by raising flags in a centralized technology system. The next critical step is academic support offices performing various levels of outreach with the students after concerns are raised to assist the students "early" to change behavior during the semester. Based on my experience in coordinating early alert programming and technology there are opportunities to scale processes and systems to support student success; however, there are barriers to leadership buy-in, faculty adoption, academic advising support, and office adoption. While achieving buy-in from academic colleges and support areas are essential to adoption, there are underlying behaviors that will be likely to influence change (Emery \& Trist, 1960; Leavitt, 1964). In addition, when technology is purchased and implemented around the processes it can have a negative impact on adoption if users of the new technology are not present in the process (Grudin, 1988).

Bolman and Deal (2008) discuss that structures must be designed to fit the organization's current circumstances including technology, people, and environment. To understand more about the relationship between technology, people, and environment a socio-technical systems approach identifies that social and technical needs must be identified prior to implementation to achieve high productivity and adoption (Cherns, 1976). Adoption that is achieved at each campus will provide a sound structure for early alert to make an impact on student persistence and gain additional performance funding dollars to meet the goals of the UM System.

The UM System campuses are decentralized and each have unique organizational cultures. This provides a complex dynamic to implement coordinated processes supported by technology because organizational structure determines behavior (Dalton, Todor, Spendolini, 
Fielding, \& Porter, 1980). User participation is dependent on each campus's organizational structure and can have a positive or negative effect on implementation. Additionally, this research aims to understand each campuses organizational structure and culture that will embrace of impede the implementation progress of an early alert system.

We know very little about implementation and adoption strategies at large 4-year public research institutions. The more we learn about the relationship between people, task, process, and technology the more awareness will be created to identify what is relevant to problems and detect problems prior to or early on in implementation. Consistent buy-in achieved at each campus will provide a sound structure for early alert to make an impact on student persistence and impact the results to gain additional performance funding dollars to meet the goals of the UM System. Currently, evidence of early alert system impact is limited (Simons, 2011; Varney, 2008). Simons (2011) explored early alert program models nationally using quantitative and qualitative data to identify which models matched institutional type and mission. The current study took the next step to provide an understanding of the relationship between people, task, structure, and technology to help practitioners that are exploring student success technologies to better understand implications, challenges and approaches to increase user adoption and increase student success their institution.

\section{Purpose of the Study}

The purpose of this case study is to understand the relationship between leadership, users (faculty and staff), technology, and the organization when implementing a campus wide early alert program facilitated by new technology. This will provide administrators and practitioners with strategic approaches to tackle future early alert implementation and adoption challenges at 4-year public universities when implementing student success technologies. The research 
provides further resources and implications to assist the institutions in this study and future institutions who are looking to implement technology. In addition, this study adds to the lack of literature of early alert system implementation at 4-year public institutions and aid campus leadership with future decision making.

\section{Research Questions}

The research questions guiding this study are, main RQ is: What is/are the organizational change(s) needed to support the implementation of early alert at each campus within a university system? Derived sub questions:

1. What campus services and offices are currently the key contributors to the implementation of early alert on each campus? (and which are missing or should be involved to contribute to a successful adoption/implementation of the system?)

2. What are the current tasks (work processes) of faculty and staff when using the early alert system? (and which tasks are missing or should be integrated in the EA system to contribute to student success?)

3. How does the perception of faculty/staff in student success/performance influence the use/adoption of early alert system?

\section{Conceptual Framework}

The framework for this study is Leavitt's (1964) Diamond, Integrated Approach to Change, which was based on Socio-Technical Systems Design (Cherns, 1976; Emery \& Trist, 1960). This framework was chosen to provide a lens to connect the research problem and research questions to the related literature. This study further contributes to Leavitt's model and by extension the models that informed Leavitt. In line with researchers such as Grudin (1988), the framework offers a socio-technical perspective to understand how people are central to technical innovations, and to understand how people are interrelated with technology structure, and tasks to impact organizational change (Sommerville, 1989). Socio-technical approaches to 
understanding organizational change has been studied and applied in a variety of fields such as organizational research, business research (e.g., knowledge management, Nonaka and Takeuchi, 1995) and in Computer Science and Informatics such as Computer-Support Cooperative Work (CSCW) (Grudin, 1988), and health care (Ackerman, Prilla, Stary, Herrmann \& Goggins, 2018). While socio-technical approaches have also been applied in higher education (Adams \& Ivanov, 2015; Pasquini \& Evangelopoulos, 2017), this study introduces a new perspective to uncover the user experience of an early alert system and introduces a new perspective to understand the variables that play a role in implementation and adoption of early alert systems.

Leavitt's (1964) Diamond, Integrated Approach to Change model evolved from social technical theory to give a broader approach to understand the relationships between people, task, structure and technology. Socio-technical approaches focus on the intersection between people and technology. Leavitt's (1964) model provides a multi-dimensional framework to understand how people, task, structure, and technology intersect when change takes place within an organization. The organizational change in this study is the implementation of early alert technology that spurs a review of tasks, processes, and roles that people provide across the organization. Each of the four areas in the model (people, task, structure, and technology) are interdependent of one another, meaning that when change takes place in one area, all areas must be evaluated to understand the impact on each of the components. The key to a successful implementation is useable integration to ensure that faculty and staff can actually use a new system, aligns with tasks, it is useable and efficient (Grudin, 1988).

The four areas of Leavitt's (1964) model—people, task, structure, and technology—are critical when implementing a new technology. The technology alone cannot produce a sustainable change. Research shows that a more promising approach is when people, task and 
structure of the organization are aligned to achieve the desired outcome of what the technology is aimed to support (Grudin, 1988). For example, to formulate a change strategy when implementing a new early alert system all four components must be considered. The catalyst for change in this study is the early alert technology. If the technology changes, Leavitt's (1964) model illustrates that there will be an impact on people; flag raisers (faculty), flag responders (academic advisors and student services staff), task; processes that were once done on paper, in a previous system, or a new process; structure; centralized or decentralized, communication flow, and workflow.

Socio-technical theory dates back to the 1940's by the Tavistock Institute for Human Relations in London. It was first introduced with innovations in coal mining and later changed focus to the design and introduction of computing systems as a Social-Technical Systems (STS) in organizational settings (Emery \& Trist, 1960). Socio-Technical Systems Theory is an approach to understanding the relationship between technology, individuals, organizations and society in work place design (Cherns 1976; Emery \& Trist, 1960). According to Cherns (1976), all organizations are socio-technical systems, where systems refers to tasks, process and people to carry out day-to-day duties. Social and technical variables must align to produce outcomes to accomplish tasks outlined by the organization (Emery \& Trist, 1960). Because technical innovations are placed in social situations, organizational dynamics matter because they affect how technology is adopted and trusted by those in the organization (Clarke, 2006). Emery and Trist (1960) argue that analysis of a technical system can produce tasks and interrelation components required to achieve technical functions. In order for the technical system to be successful, it relies on how well the social system is able to cope with the requirements. Emery and Trist discuss the interdependencies of implementing a technical system. Leavitt (1964) 
mapped the approach to organizational changes demonstrating the interdependence of each of the four areas. Leavitt argues that while all four areas are impacted it will impact structure and therefore will impact the motivation, attitudes and trust of those being impacted by the change.

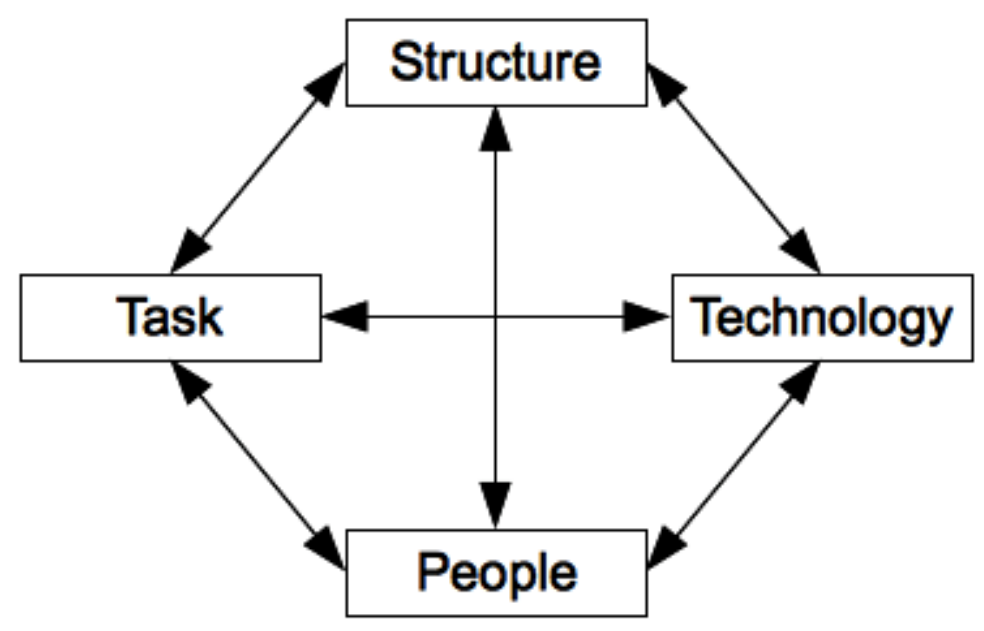

Figure 1. Leavitt's Diamond, An Integrated Approach to Change (1964).

The socio-technical systems approach identifies that social and technical needs must be identified prior to implementation to achieve high productivity and adoption (Cherns, 1976). The purchasing and implementation of a vended solution, Starfish. The technology was chosen through a request for proposals (RFP) process at the UM System. The RFP process addressed several high-end needs identified by each of the campuses that vended solutions could respond to. The design of tools, processes, people, and timing are varying internal controls at each campus. The framework states that the traditional practice to design the technology first and then put people into it leads to poor adoption and low productivity (Cherns 1976; Emery \& Trist, 1960). While the technology supports an overall need identified at the UM System level, the core components delivered and how tools and processes are implemented may have an impact in the 
overall adoption and productivity in early alert programming. Therefore, in this study, the processes/tasks, people involved, current structure and new technology have been investigated.

\section{Design of the Study}

For this study, I conducted a multisite case study. Case studies are useful for studying educational innovations (Merriam, 2009) and to find complex interrelationships at each site (Stake, 1995). This approach was relevant to find a deeper understanding of the interrelationships that technology, individuals, and the campus organization play when implementing a new initiative at each campus. The research questions that were initially selected were modified as new issues were found and constantly evaluated throughout the study (Stake, 1995). Each institution shares common characteristics of implementing a common academic early alert system, but each institution has unique leadership, users, and organizational design. The multiple cases included provided more a more robust and compelling interpretation to enhance the external validity of the findings (Merriam, 2009). An action research approach was used to improve early alert processes and technology through understanding of the unique user perspectives to produce findings to further implement effective practices.

\section{The Setting and Participants}

The setting for the research took place at all four UM system institutions in Missouri: University of Missouri (Columbia), University of Missouri--St. Louis, University of Missouri-Kansas City, and Missouri Science and Technology. To start the data collection process I sent out a recruitment email to each campus's early project manager to share more about the study asking for support and sent a request to schedule a phone interview. I worked with each early alert manager and preliminary access to participants was discussed along with negotiating a plan of action to conduct interviews with project managers and focus groups with flag raisers, flag 
responders, and leadership at each campus. A formal agreement was also negotiated between me and each early alert manager prior to conducting the study (Stake, 1995).

I coordinated with the early alert manager at each campus to identify specific users that relate to institutional conditions (Kuh, Kinzie, Buckley, Bridges, \& Hayek, 2006), which included faculty and staff representing first year experience, financial aid, academic support, peer support, and retention services. Once members were identified, I sent focus group invitations to stakeholders to participate in the study. Focus groups consisted of a mix of leadership, instructors, and academic support staff in each focus group. Focus groups were videotaped and lasted 60-90 minutes, and participants consented to be videotaped.

I chose stakeholders who do use the early alert system and those that participated in the early alert process. There are three core roles in the early alert process; flag raisers, flag responders, and students. Students were not included in the research questions as a part of this study. The focus was to have an organizational perspective on the institutional staff and faculty involved in using the new technology. I did not reach out to members not using the technology because the study focuses on those that have directly experienced the technology and processes. Members identified as flag raisers included tenure track and adjunct faculty instructors that have participated in early alert. Members identified as flag responders were academic advisors, department support staff, retention services staff, registrar staff, and first year experience advisors who monitor, provide outreach, and meet with students. Once key actors were identified in each area at each institution, I emailed (see Appendix A) all proposed participants inviting them to participate in the study at their respective campus. Consent documents (see Appendix B) to participate were given to gain written consent of the stakeholders. The consent document 
included that participants can choose to withdraw their participation from the study at any time (Stake, 1995).

\section{Data Collection Tools}

Six interviews and six focus groups were conducted with 42 key stakeholders involved in the early alert implementation at each institution. Four interviews were conducted, one at each campus, with each campus's project manager to best understand the organizational structure design of each UM System campus early alert program, approach in implementation, and populations targeted through the use of the early alert tools. Two additional interviews were conducted with participants from UMSL that were unable to attend the focus group. Next, six focus groups were conducted to understand the intersection of multiple perspectives from all users engaging in the raising of flags and outreach functions of early alert. UMSL and S\&T had one focus group and UMKC and MU each had two groups. Each member of the focus groups brings a different perspective and campus experience. Focus groups included leadership, academic advisors, instructors and student service coordinators. Focus group participants were critical to best understand how the UM System decision affects early alert adoption, how their perception of student success impacts their role, and how technology, individuals, and the campus organization influence the adoption of a campus early alert program. Since each member is responsible for different aspects and coordination of early alert, it was informative to understand the evolution, coordination, and support for early alert.

The information that I gained from the early alert project manager was used to design focus group questions, reduce my own personal bias, and ask more in depth and probing questions to draw out a deeper understanding from participants (Merriam, 2009). In addition, the UM System objectives contributed the focus group questions to understand implementation and 
how buy-in decisions were influences to best understand if the aim and the outcome were consistent (cite). The interview (see Appendix C) and focus group (see Appendix D) questions were developed from, CRI documentation, project manager feedback, and Socio-Technical Systems Theory Intervention Questions (Appelbaum, 1997) and Readiness of Technology Adoption Self-Assessment (Karp \& Fletcher, 2014)

Positionality as the researcher was an important consideration as I conducted focus group work and my own awareness of my own campus role being an influence in the research setting. I acknowledged in interviews and focus groups during the introductions that I work with early alert at the MU campus, set group rules and norms and asked the participants if they have questions. During the grounding of rules I shared that they are encouraged to do the talking, that there were not right or wrong answers, and what is said in this room stays in the room. I shared that I wanted participants to be comfortable in sharing when sensitive issues arise during the conversations. Focus group questions were designed and arranged by hypothetical, devil's advocate, ideal position, and interpretive questions (Merriam, 2009). I followed a semistructured interview protocol to understand the participant's viewpoint (Merriam, 2009). This allowed the focus group members to have free flowing conversations and help make participants comfortable with the process.

Prior to the start of the focus group participants were asked to fill out a short questionnaire to identify their name, role at their institution, role in early alert implementation and programming, and special populations of students that they target though the use of early alert flags. During and after the focus group session I took notes of observations and themes that emerged during the focus group. In addition, before conducting research I acknowledged, understood, and abided by polices set by the Institutional Review Board (IRB). IRB's purpose is 
to ensure the ethical treatment of participants (Pritchard, 2002). I obtained IRB approval before conducting research of this study. I also worked with my dissertation advisor for guidance.

\section{Data Analysis}

The process of data analysis includes interpretation and defining the relationship between concepts (Stake, 1995). I applied holistic multiple case study design that focused on the influence of early alert implementation by exploring the experiences of flag raisers and flag responders (Yin, 2009). Finally, the specific methods interviews, focus groups, and document analysis provided a collection of data that addressed the research questions and highlighted the participants experience (Creswell, 2013).

I used direct interpretation and categorical aggregation processes simultaneously to find direct meaning and categorize similar instances found during interviews and focus groups (Stake, 1995). I examined the qualitative data through coding of observation field notes, six participant interview transcripts, and six focus group transcripts (Emerson, Fritz \& Shaw, 2011). Coding is the process of making notations next to important information that could be relevant to answering research questions (Merriam, 2009). While reading qualitative texts, I coded all data with an open coding method to further interpret data and reflect on meaning. This allowed me to identify reoccurring patterns across the data to answer the research questions. I grouped the coded data into Leavitt's (1964) four categories that illustrate the relationship between variables findings as they related to early alert implementation: structure, task, people, and technology (see Figure 1). During the data analysis, I continuously reviewed the coding process. As I coded each institution's set of data I created consistent codes and categories to identify groupings of data that responded to my research questions (Merriam, 2009). I identified themes and categories and merged these into a master list to support the research questions (Creswell, 2013). I reviewed the 
data by themes and patterns by respondent type, campus responses, and overall across the system to compare responses.

As themes emerged from focus groups, I evaluated the responses using respondent validation (Merriam, 2009). This gave me the opportunity to go back to the participants regarding conflicting responses, validate their responses, rule out misinterpretation, and identify any bias. I found sponsor bias at two campuses in responses from leadership and went back to users to confirm responses and interpretation. Bias can be an issue in this way because the organization and leadership member's beliefs influences how users answered focus group questions. In addition, I used a data source triangulation method to examine if the case remained the same at each campus. I triangulated findings though multiple data sources. Sources included: interview transcripts data, focus group transcript data, CRI documentation, and support of an external validator. Though the data analysis process I looked for frequent themes to respond to the research questions across campuses to identify answers to the research questions for each institution and across the UM System. I also identified similar responses by flag raisers and flag responders to understand similarities across institutions and differing responses by person type.

\section{Ethical Considerations}

Maintaining an ethical approach to protect participants was a priority while conducting research. I took an action research approach to understand the perspectives of users of early alert technology (Kemmis \& Wilkinson, 1998). Using this approach provides an opportunity to observe the process and changes through the experiences of the early alert users to further improve the professional practice of early alert. My understanding and bias of early alert was applied when conducting focus groups, navigating instutistional jargon, and applying meaning to the responses. While I was in the field, I was aware of my consciousness when participants 
looked to me for validation of their statements or asked for my own thoughts and interpretations on their feedback during focus groups (Stake, 1995, p. 41). It is important to consider advantages and issues of personal bias and confidentiality because of my current role in student success technology and early alert program coordination. Drake and Heath (2011) discussed that is it important that the researcher is accountable and anticipates ethical issues before research begins.

I interviewed participants who were aware of my professional role outside of my research and it was important to keep a research focus and not allow my personal bias to negatively affect the study. I used the advantage of my bias and professional knowledge to help navigate institutional jargon and best navigate focus groups to provide a richer investigation and understanding of responses to apply to practice. In order to be aware of my own bias I kept an awareness of responses, the way I asked open-ended questions, body language of participants, and observed actions of participants. I kept a research journal to document my thoughts and interpretations during the data collection process and analysis stages to be aware of my personal bias. Interview and focus group data were locked in a cabinet where only I had access. In addition, all audio recordings were shared on a private drive.

As the researcher of this study, I also have my own bias that can be influenced insider knowledge about early alert system at the University of Missouri Columbia campus because I am the early alert manager at the University of Missouri. My experience adds value to the study to be designed in an applicable way, but it was important to identify ethical issues and risk when conducting interviews, focus groups, and coding data. I was initially concerned about the possibility that the participants may have felt persuaded to participate because of knowing my current position. I also anticipated that participants might not have given honest responses to 
protect their employment or to maintain peer relationships if they shared negative feelings about early alert experiences in front of a boss or peer. I found that during my research the participants were greatly appreciative that someone was interested to learn more about this topic and they were eager to learn of the results of the research. I was also very aware to not impose judgement when asking questions. Rather than infusing my own bias during interviews and focus groups I would ask questions like "tell me more" and "why do you feel that way?" I was very much aware of myself during data collection and analysis. I kept a reflective journal during my research to address any bias that may positively or negatively affect the study. Lastly, each campus's project manager reviewed my results and interpretations. Each campus gave feedback regarding delivery of results so it could be presented in a way that is well received by leadership.

\section{Limitations, Assumptions, and Design Controls}

A limitation of the design is that the study is solely focused are large public institutions. Small institutions may not find the information transferable to apply. Students were not included in the study. These elements are beyond the scope of the research, but could be researched in future studies. Interview and focus group responses collected were an accurate reflection of opinions and experiences of participation and not changed for any reason. I also kept a journal to acknowledge any bias or concerns during the study.

It was not assumed at any time during the data collection process that users understood technical terminology of the system. If there was a question to clarify, a definition discussed, the researcher asked for clarification to best understand the data and not assume that all members understood terminology. An assumption that I have is that early alert systems and student outreach are valuable processes and technology should be valued to support these systems. Lastly, as a design control I consulted with an external validator. This person holds a campus 
role at the UM System and full time staff role at the University of Missouri- Columbia campus. Validation of the study was received. The validator is close to the UM System CRI initiatives, but removed enough from early alert to validate my descriptions and background of the CRI to give a clear representation.

\section{Definition of Key Terms}

Early Alert. "A systematic method of recording and communicating student behaviors that contribute to student attrition that can aid in student retention efforts" (Tampke, 2012, p. 524).

Flag. A technical tool that is a course-based indicator that a student is not performing well in a course based on instructor expectation. Flags are the first step in a systematic intervention process.

Flag Raiser. A person who raises a flag on a student regarding an academic concern in a course.

Flag Responder. A person who has a task to manage flags on a group of students, ability to see flag information in the technology platform, and outreaches to the student to resolve the academic concern.

Kudos. A technical tool that is a course based indicator that a student is performing well in a class.

Leavitt's (1964) Diamond, An Integrated Approach to Change. A framework to approach the understanding of the relationship between task, people, structures, and technology in an organization.

Outreach. Responding to a flag by sending a student an email or calling a student regarding the academic concern raised. 
Progress Survey. A structured tool sent out to instructors during a milestone week during the semester asking for specific feedback regarding student progress that includes flags, kudos, and/or referrals.

Socio-Technical System Theory. An approach to understand the relationship between technology, individuals, organizations and society in work place design (Cherns 1976; Emery \& Trist, 1960).

User. An instructor or staff member using early alert technology to support the early alert process.

\section{Significance of the Study}

Early alert systems are a significant tactic campuses are deploying across the nation to respond to performance funding to strategically support student success to increase retention and graduation rates; however, there is little to no literature that discusses the implementation of early alert system at large 4-year institutions. The UM System CRI committee aimed to further support retention efforts by introducing early alert technology to systematically support student success as a way to respond to the state of Missouri's performance funding bill. The initiative was lead with technology as a central focus and in order to support implementation and each campus took different approaches to support processes with new technology. However, there is a lack of understanding how technology impacts an individual's adoption of a new system. Early alert systems are costly, time intensive applications that has the ability to transform the lives of students. Without clearly defined processes, people that have it defined in their job descriptions, integration in campus goals, ongoing training and evaluation it may ultimately fail.

This study is unique because each of the campuses that are a part of a university system with differing organizational structures cultures, and readiness to respond to change. This study 
provides a unique lens to best understand how campus structure, task, people, and technology are interrelated and the unique approaches applied to support early alert at each campus. In addition, the case study also reveals strategies and challenges that inform large institutions that are seeking to implement and invest resources toward adoptions strategies.

\section{Summary}

Early alert programs and technology systems are a new and evolving practice at large 4year public institutions. The organizational structure, perception of student success, and intersection of technology, people, task and structure are key areas to understand in order to advance conversations regarding implementation and user adoption of early alert systems. The conceptual framework of social-technical theory provides the first steps to understand the relationship between people and technology. This framework further evolves into a later sociotechnical model of Leavitt's (1964) Integrated Approach to Change Framework provides a way to understand the complex interrelationships to further explore the technology adoption challenge at each UM System campus. In addition, early alert systems provide an accountability measure to demonstrating student outcomes to provide additional funding to intuitions to reinvest in student success efforts. The interdependent relationship between people, structure, tasks, and technology are critical components to research and provide implications for practice to aid administrators in implementation and adoption planning to address early alert programming to support student success initiatives at 4-year public institutions. 


\section{SECTION TWO:}

\section{PRACTITIONER SETTING FOR THE STUDY}

Early alert practices offer institutions systematic approaches to identify and intervene with students showing at-risk behaviors (Tampke, 2012). The institutions in this study are engaging in early alert as a retention tool as one of many ways to respond to performance funding measures set by the state of Missouri. While policy plays a distinct role in leadership decision making, leaders need to have an understanding of the interdependent relationship between people, tasks, structure, and technology. To be effective, the student success program must overcome the challenge of integrating the new, required technology supported early-alert practices. This requires members of the institution's leadership be willing to influence the development and adoption of these processes that will be needed to sustain the early alert program (Bolman \& Deal, 2008). An understanding of this relationship will benefit the planning process, implementation, and adoption strategies, of an early alert program supported by new technology. Socio-technical theory and leadership theory provides context to frame the early alert implementation process. This section will provide a history of the organization, discuss organizational structure and political frames, share leadership questions that may impact implementation, and implications for research in the practitioner setting.

\section{History of Organization}

The University of Missouri (MU) was established in 1839 as teaching and research driven institution (University of Missouri is referring only to Columbia campus). The University of Missouri System (UM System) is a higher education system with four campuses in the state of Missouri located in Columbia, Rolla, St. Louis, and Kansas City. In 1870, a University of Missouri campus was established in Rolla, Missouri. The University of Missouri campuses in St. 
Louis and Kansas City were last to join in 1963 completing the four campus system. Today, the

UM System has 77,000 students, health care and extension offices in every county in the state of

Missouri (University of Missouri System, 2016). The UM System mission is as follows:

The mission of the University of Missouri, as a land-grant university and Missouri's only public research and doctoral-level institution, is to discover, disseminate, preserve, and apply knowledge. The university promotes learning by its students and lifelong learning by Missouri's citizens, fosters innovation to support economic development, and advances the health, cultural, and social interests of the people of Missouri, the nation, and the world. (https://www.umsystem.edu/)

The UM System is governed by a board of curators who are appointed by the governor and confirmed by the Missouri Senate. The UM System has one president, general counsel and secretary of the board who report to the board of curators. The president of the UM System has a chancellor at each institution, Chief of Staff, Vice President for Academic Affairs, Vice President of Finance, Vice President for Human Resources, Vice President for Information Technology, and Vice President for University Relations (University of Missouri System, 2016).

\section{University of Missouri}

The University of Missouri (MU) refers to only the Columbia campus and is a public land grant institution that was established in 1839. The fall 2017 enrollment was 30,870 and undergraduate enrollment was 23,817. The University of Missouri was an open enrollment institution until the Civil Rights movement in the 1960s and then became a moderately selective institution (University of Missouri, 2017). MU has a diverse enrollment with students from every county in Missouri, every state in the nation and 120 countries. "MU offers more than 300 degree programs through 19 colleges and schools and is one of only five universities nationwide with law, medicine, veterinary medicine and a nuclear research reactor on one campus" (University of Missouri, 2017). MU is also the largest employer in the state of Missouri with 13,000 employees (University of Missouri, 2017). The MU Mission is: 
Our distinct mission, as Missouri's only state-supported member of the Association of American Universities, is to provide all Missourians the benefits of a world-class research university. We are stewards and builders of a priceless state resource, a unique physical infrastructure and scholarly environment in which our tightly interlocked missions of teaching, research, service and economic development work together on behalf of all citizens. Students work side by side with some of the world's best faculty to advance the arts and humanities, the sciences and the professions. Scholarship and teaching are daily driven by a commitment to public service - the obligation to produce and disseminate knowledge that will improve the quality of life in the state, the nation and the world. (http://missouri.edu/about/mission.php)

In addition, MU is led by team of vice chancellors and directors who report to the chancellor concerning the following areas; academic affairs, finances, graduate studies and economic development, university advancement, student affairs, operations, health affairs, marketing and communications and athletics (University of Missouri, 2016b).

\section{University of Missouri-Kansas City}

The University of Missouri-Kansas City (UMKC) was established in 1933 and became a member of the University of Missouri System in 1963. UMKC has three campuses: Volker, Health Sciences, and a Northland location. The institution has 14 schools and colleges with a fall 2015 enrollment of 16,699 and undergraduate enrollment of 8,350. The UMKC campus is very diverse with students representing all 50 states and 79 countries. The institution employs 1,172 full-time and part-time faculty and keeps a student faculty ratio of 1:13. The UMKC campus also retains $49.9 \%$ of students to work in the Kansas City area (University of Missouri-Kansas City, 2016a). The UMKC Mission is:

to lead in life and health sciences; to deepen and expand strength in the visual and performing arts; to develop a professional workforce and collaborate in urban issues and education; and to create a vibrant learning and campus life experience. (http://www.umkc.edu/chancellor/mission-vision.cfm)

In addition, UMKC is led by team of directors, vice chancellors, and a provost who report to the chancellor concerning the following areas: academic affairs, information services, online and 
distance learning, academic schools and colleges, athletics, diversity and inclusion, student affairs, enrollment management, finances, human resources, marketing and communications, and advancement (University of Missouri-Kansas City, 2016b).

\section{University of Missouri-St. Louis}

The University of Missouri- St. Louis (UMSL) was established and became a member of the University of Missouri System in 1963. The institution has 10 schools and colleges with a fall 2016 enrollment was 16,989 and undergraduate enrollment of 13,898. UMSL enrolls students from across all 50 states and 63 countries. Over 65,000 UMSL graduates are employed in the St. Louis area (University of Missouri-St. Louis, 2016a). The UMSL mission is provided below:

The University of Missouri-St. Louis provides excellent learning experiences and leadership opportunities for a diverse student body. Outstanding faculty and staff, innovative research, and creative partnerships foster synergies that advance the welfare of our stakeholders and benefit the global society. (http://www.umsl.edu/services/academic/About\%20Us/mission.html)

In addition, UMSL is led by team of vice chancellors, directors and provosts who report to the chancellor concerning the following areas; diversity, technical services, academic affairs, research, student affairs, and advancement (University of Missouri-St. Louis, 2016b).

\section{Missouri University of Science and Technology}

Missouri University of Science and Technology (S\&T) is a public land grant institution established in 1870 and became a part of the University of Missouri system in 1964. S\&T has two schools: College of Engineering and Computing and College of Arts \& Science, and Business (Missouri University of Science and Technology, n.d.). The fall 2017 enrollment was 7,969 and undergraduate enrollment was 6,801 (Missouri University of Science and Technology, 2017). The S\&T mission is "Missouri S\&T integrates education, research and application to 
create and convey knowledge that serves our state and helps solve the world's great challenges" (Missouri Science \& Technology, 2017). In addition, S\&T is led by team of vice chancellors, directors and a provost who report to the chancellor concerning the following areas; global and strategic partnerships, human resources, diversity and inclusion, academic affairs, finance and administration, advancement and student affairs (Missouri Science and Technology, 2016).

\section{Organizational Analysis}

In order to understand the challenges of implementing a new student success technology, it is important to understand the organizational structure of each of the UM system campuses. Each campus has its own leadership and divisions within each of their campuses. In addition the UM System has a central governance structure, Academic/Student Administrative Oversight Committee (ASAOC), who supports central initiatives for collaboration between the four campuses. In spring 2013, the ASAOC proposed a "comprehensive approach to use common advising software tools, tailoring software to meet both campus and system needs, implementation workshops, and creating conditions necessary to improve student retention and ultimately graduation" (internal document, CRI Source Document). To execute and support the vision ASSOC appointed the, Comprehensive Retention Initiative (CRI), a task force of core leadership from each of the four campus.

The CRI committee was made up of campus leadership who served as voting members who were the key decision makers representing each campus. Each member represented their institution's best interest and provided context regarding organizational leadership, culture, processes, and resources available to carry out the decisions of the CRI committee. It is also the committee members' responsibility to share the decisions of the CRI, how it affects their campus, and assist with strategic planning to carry out the decisions made at the system level. In 
order to understand the challenges of implementing technology, it is important to understand the structural and political frames of a 4-year public institution. In addition, while structural and political frames are most applicable to this study, human and symbolic should be understood (Bolman \& Deal, 2008).

\section{Structural Analysis}

Organizational structure determines behavior (Dalton, Todor, Spendolini, Fielding, \& Porter, 1980). Bolman and Deal (2008) discuss that structures must be designed to fit an organizations' current circumstances including technology, people, and environment. In addition, if problems arise performance can suffer from lack of structure (p. 47). A large part of creating a successful structure is putting people in the right role and relationship to achieve goals (Bolman \& Deal, 2008). Bolman and Deal's (2008) structural frame provides an understanding to organizational structure by describing structural imperatives that influence the organization's social structure. These include: size and age, core process, environment, strategy and goals, information technology, and nature of the workforce (Bolman \& Deal, 2008). Size and age refers to how many employees will be affected and how old the company is. The greater number of people and the older the company is the more complex it will be to navigate (Bolman \& Deal, 2008).

In addition, core processes and technologies must align with the organization's structure. Bolman and Deal (2008) discussed that strategy and goals are often communicated by leadership and will shape the structure of an organization. Information technology is an essential element because "by increasing flow of information, improved technology reduces uncertainty" (p. 67) and provides all users with the same information to efficiently carry out their work. Lastly, the nature of the workforce is defined as the demographics of the people at the company mean that 
as the demographics of the people varies at different companies so does the work, how they do the work, and the type of skill each employee has to carry out a task (Bolman \& Deal, 2008). Mintzberg's (1980) divisionalized form provides the best representation of a structural model at each of the UM System campuses. Departments at 4-year public institutions are decentralized and are less likely to communicate with one another (Mintzberg, 1980). This model best represents the organizational infrastructure that is present at each campus and illustrates the potential barriers that will influence the behaviors of leadership, instructors and staff involved in the early alert process. While the five basic parts of the organization (Mintzberg, 1980) work together to achieve goals of the organization, each of these areas in the divisionalized form must be treated as independent systems with a single set of goals to the whole (Mintzberg, 1980). Mintzberg introduces the five basic elements of organizational structure: strategic apex, operating core, middle line, techno structure, and support staff. All parts work together to carry out the organization's mission, vision, and goals.

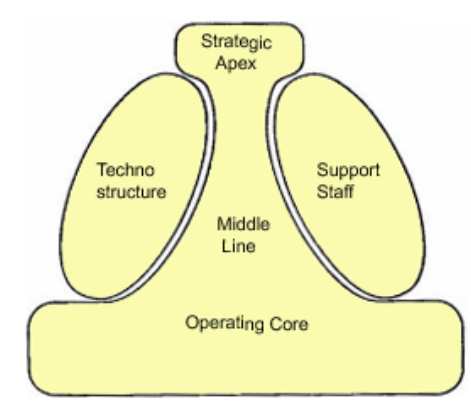

Figure 1. Mintzberg's (1980) Five Basic Elements of Organizational Structure

Mintzberg (1980) discussed that power factors also have effects of the behavior of staff within the structure. In addition, Mintzberg provided examples of how technology has influenced the evolution of the techno structure and support staff to emphasize the coordination of all parts within the model. Of the parameters associated with the five basic parts, vertical 
decentralization and horizontal decentralization describes how power flows vertically and horizontally between how decisions and delegated from the top down or between the middle line and support staff (Mintzberg, 1980). Most divisionalized form structures are old in age, very large, have virtually no automation to any outputs, and power resides in the middle line. An implication of this structure is that "It is difficult to develop performance measures because each area is treated as a single entity and have autonomy from the whole of the organization" (Mintzberg, 1980, p. 335).

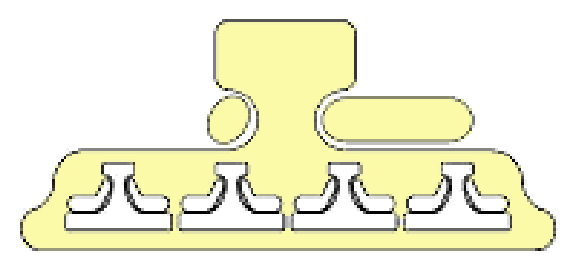

Figure 2. Mintzberg's (1980) Divisionalized Form (1980)

Mintzberg's (1980) models provide a sound historical context for understanding organizational behavior and provides application as to how the structural elements can change. This model gives the best representation to describe the structure of four-year public research institutions. In addition, there are many external pressures from the UM System and institutions to make decisions in a timely manner and often times leadership is slow to respond to external change because they work in their own divisions. Bolman and Gallos (2011) discussed academic silos as a structural dilemma when making decisions with other areas because they have an established independence from one another. Each campus is independent of one another with their own mission, vison, and culture that creates autonomy. When decisions are made at the UM System level each campus has their own "personality" and response to change because each campus has independence from one another. Each campus will also have its own internal divisional challenges. This creates an additional level of challenge for any effort to implement 
something that is the same product or is to use the same process on all four campuses. They will vary within and from each other. Unless there are reliable vertical systems in place and until this changes it will be hard to bring about change to implement a new system at each campus (Bolman \& Deal, 2008). This review shares the need for coordination with leadership to communicate and support new initiatives so the new work and tasks to be accomplished with in the divisions can be adopted.

\section{Political Analysis}

Bolman and Deal (2008) introduce the political frame as a part of daily organizational life. Bolman and Deal outlined five political propositions: organizations as coalitions, coalition members have enduring differences, important decisions involve allocating scare resources, scare resources and enduring differences make conflict central and power the most important asset, and goals and decisions emerge from negotiating for positions (p. 195). This is relevant to the study to provide insight into the daily dynamics of making decisions at a system and campus level. It provides further understanding on how decisions are influenced from a top down approach from the UM System to each campus. Influences can include conflicting opinions on uses of technology to support student success, timing in rollout of new technologies, various needs of users on each campus, and potential negative implications from attempting to change practice at the department level.

The conflicts of power within the taskforce (CRI) committee to decide on retention strategies and investment of time and people can create political activity because of “interdependence, divergent interests, scarcity of resources, and power relations" (Bolman \& Deal, 2008, p. 194). The CRI committee is a coalition that has been operating with members from different campuses who have differing interests that predictably favor their own campus 
perspectives. The CRI committee members agreed that there has to be a strategic response to increase metrics at each campus to position the UM System to obtain the desired level of performance funding. Each campus agreed that student success technologies will be a priority to implement. MU and UMKC already decided that they wanted an early alert system during the time period where the UM System determined that the decision needed to be comprehensive to serve all four campuses. The UM System wanted the four campuses to purchase the same solution and did not assess the readiness or need, thus adding another layer of complexity to the effort. In addition, a significant concern is scarce resources and capacity issues at each campus influencing their ability to onboard new technologies and programs.

A key issue is the political battle over monetary resources at the system level. The need for resources to support the implementation and adoption at each institution is a financial and political struggle between the UM System and each campus. Bolman and Deal (2008) discussed that scarce resources will create the intensity of politics in difficult times. The intensity of the monetary issues at each campus has resulted in varying approaches to implement a new student success technology. For example, each campus has different coordinating structures for implementation of early alert processes, policies, and software. Some campuses hired a new fulltime staff member dedicated to the project. Other campuses rolled the duties into an existing fulltime position.

Power is another political issue to consider when understanding the UM System, each campus, and CRI committee. Power influences the timing of the implementation, who controls the resources and the perceptions of what is deemed successful. Mapping the political terrain also gives insight to assessing the internal and external players who will be involved in implementing a new system (Bolman \& Deal, 2008). The CRI committee is made up of vice 
provosts, student information systems staff, academic affairs representatives at the system level, registrars and student success coordinators. The Senior Associate Vice President for Academic Affairs at the UM System serves as the chairman to engage internal and external players who can positively influence decisions. However, the CRI members are responsible for engaging their own internal campus players that are not on the CRI committee. They are faculty members, student service directors, and academic advising directors. They were included because they work more closely with the tasks, processes, and people and will be the "boots on the ground" adopting new processes and implementing the system in the manner directed by the CRI committee's decisions (B. Selman, personal communication, January 2018).

\section{Leadership Analysis}

Leadership is a process where people are emotionally and actively involved to shape ideas and expand available options to long-standing processes (Northouse, 2012). Various leadership tactics must emerge to successfully transform the UM System campuses in their current state to adopt new technology and approaches. Leadership at the CRI committee level is the first level of leadership influence during the phases of planning followed by leadership influences at each campus to implement new technology. A committee or taskforce demonstrates leadership when collectivity the members are emotionally and actively involved in shaping ideas and expanding options to a long-standing process (Levi, 2014). Transformational leadership takes leadership to an emotional level where individuals who exhibit transformational leadership are concerned with values, ethics, standards and long-term goals (Northouse, 2010).

Transformational leaders move followers to achieve more than the norm of what is expected of them (Northouse, 2012). Transformational leadership is best applied to understand the leadership 
that is necessary to transform the CRI committee's ideas into tangible programs, processes, and technology adoption.

The influencing dynamic of transformational leadership is largely at play when motivating committee members and advising and student services staff to adopt a new process and technology to increase the likelihood for success of students at the UM System campuses. Transformational leadership is a trait that must be present for this project to be successful. Because it is an exceptionally complex set of circumstances, the level or demonstrated leadership needs to be at a higher level of transformation. This will ensure that the energy and engagement level is sufficient to motivate the individuals involved to push their the challenges of maneuvering past the power struggles, the historic differences in approach and structure as well as the human dynamics that can derail it. The following questions are important to consider when assessing leadership at the UM System and campus levels:

1. How does leadership play a role in implementing a new system?

2. How can issues of leadership inform the context with each campus and the system?

3. How does a leader engage other leadership in entities (colleges, schools, support services) that require buy-in?

4. What are the leadership issues to keep in mind?

5. How does a leader listen to others needs when they don't align or agree with the new practice being proposed?

6. How do leaders influence campus stakeholders to adopt a new practice? While transformational leadership is a leadership theory that provides context to transforming and motivating people, it is important to share that my perspective is lacking regarding which leadership styles are most used or required to achieve the best results for the UM System CRI 
committee and leadership needs at each institution. From my personal experience, the CRI committee is made up of leadership who can provide a broad and in-depth context to student retention strategic planning and challenge the status quo to create change. However, it is important to not solely lean on transformational leadership as the only leadership dynamic used to support the ongoing planning to implement early alert technologies at the UM system campuses.

\section{Implications for Research in the Practitioner Setting}

The purpose of this study is to gain further insight concerning the implementation and adoption of early alert systems at 4-year public institutions. Organizational and leadership analysis of the UM System and each campus are relevant to provide context of the study and support the research questions. This analysis supports the study to best understand each campuses early alert structure, influence of the UM System, relationship between people, task, and technology, and perception of student success on technology adoption. The adoption of new early alert technologies ignites a process of change for each campus. Change is inevitable as higher education institutions try to find new programs to support campus student success efforts. Change is influenced by the organization, culture, and leadership decisions. Stakeholders are crucial for adoption and it is important to receive their feedback, understand their core tasks, and provide supportive resources to review and integrate new tasks with advising and student services offices. In addition, to implementing a new technology leadership should consider the communications needed to shape the path of implementation and reinforce the importance of the system with overall assessment outcomes. This will create a new culture around student success by communicating outcomes to motivate and inform those who are engaging with new early alert technologies. 


\section{Summary}

The implementation of early alert technologies at each UM System campus started as a top down approach. However, each campus had a different readiness to implement and differing resources to support early alert technology. Conducting focus groups and interviews with those involved in early alert implementation at each campus, observing and coding their experiences, and the understanding of organization and leadership theories provides a richer context to thoroughly understand the relationship between people, task, and technology to respond to the research questions. The information gathered can be further shared and used by UM System leadership, campus leadership, and stakeholders at each campus with implications to review current structures, policies, task expectations, review processes, and collection of data. Research has been gathered from scholarly sources and integrated with in the findings to provide scholars and practitioners with implications to support early alert adoption at their campus. 


\section{SECTION THREE:}

\section{SCHOLARLY REVIEW FOR THE STUDY}

In 2014, the Missouri's performance funding bill spurred many Missouri higher education institutions to evaluate current programs and planning to align institutional resources with the new funding appropriations set by Senate Bill 492 (2014). The University of Missouri System responded to performance funding by developing a Comprehensive Retention Initiative (CRI). The CRI committee coordinated a strategic planning process and identified many objectives, one of which was to implement a menu of student success technologies to support retention and graduation. One of the technology requirements was to support a campus wide academic early alert system at all four UM system campuses. Early alert practices and technology are new and evolving in higher education.

Early alert systems are defined as "a systematic method of recording and communicating student behaviors that contribute to student attrition that can aid in student retention efforts" (Tampke, 2012, p. 524). Campuses from around the United States are adopting new practices supported by technology to reach out to students about academic, financial, social, and health concerns raised by a staff or faculty member that can impact student persistence (Greenfield, Keup \& Gardner, 2013). Students experiencing academic difficulty can benefit from effective interventions that then improve their chances of being retained (Tampke, 2009). Early alert systems are defined as "a systematic method of recording and communicating student behaviors that contribute to student attrition that can aid in student retention efforts" (Tampke, 2012, p. $524)$.

Retention of students is a constant topic of conversation and concern at many universities. Unpacking why students leave and contributing factors that aid in a student leaving 
college is an ongoing conversation in retention literature. A student's initial intentions and commitments along with pre-entry attributes such as family background and interests can impact persistence to degree (Bean, 1990; Tinto, 1975). In addition, at-risk students come to college with a variety of limiting factors, such as: academic, motivational, psychosocial and financial factors that can impact student's persistence (Barefoot, 2004). Institutions determine many of these areas by academic preparedness of ACT scores, high school core courses, and high school grade point average. Many institutions also determine at-risk by minority, first generation status, low socioeconomic status, and Pell eligibility (Gelnter, 2001; Murtaugh, Burns, \& Schuster, 1999).

Early alert systems aid institutions with increasing student retention on campus by identifying several risk factors for student success (Tampke, 2012). Early alert systems can be configured as a tool to help instructors and student success coordinating staff to identify academic, financial and engagement variables that will indicate if a student is on or off track (Simons, 2011). Current conceptual context to guide the review of literature surrounding early alert systems is the retention research that says, "Students who do not experience academic success during their first semester of attendance will be less likely to be retained" (Greenfield et al., 2013, p. 179).

\section{Leavitt's Diamond Model}

The framework for this study is Leavitt's (1964) Diamond, Integrated Approach to Change, which was based on Socio-Technical Systems Design (Cherns 1976; Emery \& Trist, 1960). This framework was chosen to provide a lens to connect the research problem and research questions to the related literature. This study further contributes to Leavitt's model and by extension the models that informed Leavitt. It offers a socio-technical perspective to 
understand how people are central to technical innovations, and to understand how people are interrelated with technology structure, and tasks to impact organizational change. Socio-technical approaches to understanding organizational change have been commonly offered in the businessconsulting fields and in health care, but not in higher education.

Leavitt's (1964) Diamond, Integrated Approach to Change model evolved from social technical theory to give a broader approach to understand the relationships between people, task, structure and technology. Socio-technical theory focused on the intersection between people and technology. Leavitt's (1964) model provides a deeper multi-dimensional framework to best understand how people, task, structure, and technology intersect when change takes place within an organization. The organizational change in this study is the implementation of early alert technology that spurs a review of tasks, process, and roles that people provide across the organization. Each of the four areas in the model (people, task, structure, and technology) are interdependent of one another, meaning that when change takes place in one area, all areas must be evaluated to understand the impact on each of the components. The key to a successful implementation of change is to find the balance that satisfies all four components.

Figure 1. Leavitt's (1964) Diamond, An Integrated Approach to Change.

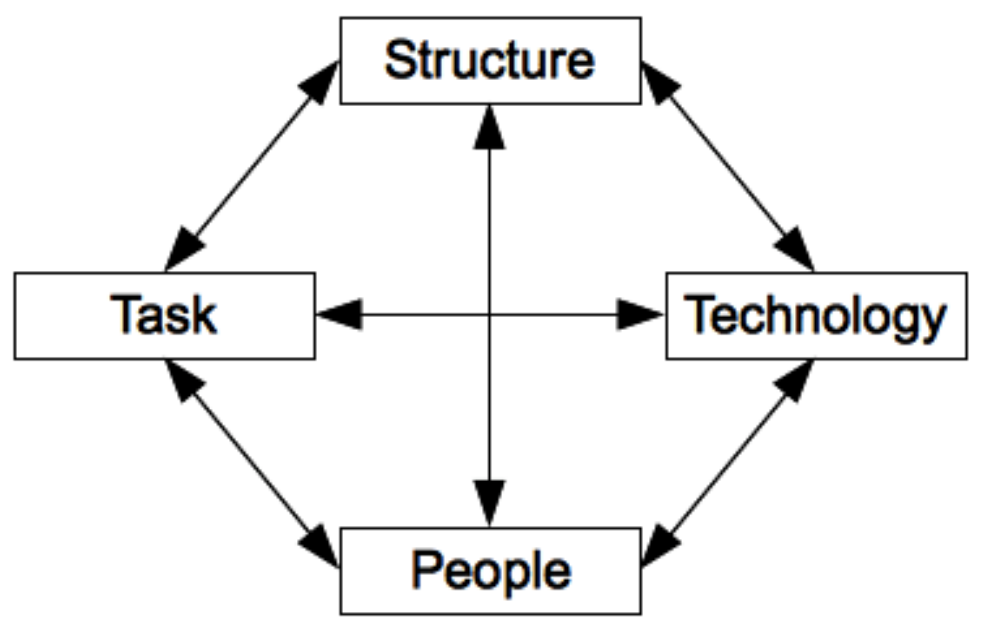


The four areas of Leavitt's (1964) model—people, task, structure, and technology—must be accounted for when implementing a new technology. The technology alone cannot produce a sustainable change. People, task and structure of the organization all must be evaluated to achieve the desired outcome of what the technology is aimed to support. For example, to formulate a change strategy when implementing a new early alert technology all for components must be considered. The catalyst for change in this study is the early alert technology. If the technology changes, Leavitt's (1964) model illustrates that there will be an impact on people; flag raisers (faculty), flag responders (academic advisors and student services staff), task; processes that were once done on paper, in a previous system, or a new process; structure; centralized or decentralized, communication flow, and workflow.

This framework provides a tailored lens to understanding how people, processes, organizational structure of each campus, and technology influence adoption of a campus wide early alert program. This framework was chosen to best understand technical and social underpinnings as to how the implementation of an early alert technical application impacts the organization. In addition, to more thoroughly understand the technical and social relationship, the dynamics and between technology, people, tasks, and structure are essential to understand the influences to early alert system adoption. Leavitt's (1964) model discussed gives relevance and provide real-word meaning to practitioners interested in this topic.

\section{Socio- Technical Systems}

Socio-technical theory dates back to the 1940s by the Tavistock Institute for Human Relations in London. It was first introduced with innovations in coal mining and later changed focus to the design and introduction of computing systems as a Social-Technical Systems (STS) in organizational settings (Emery \& Trist, 1960). Emery and Trist (1960) recognized. that 
industrial attempts to change practice should include research and be understood to include both machines and the organization. Meaning that technology alone should not lead the change in an work environment. Socio-Technical Systems Theory is an approach to understanding the relationship between technology, individuals, organizations and society in work place design (Cherns, 1976; Emery \& Trist, 1960). According to Cherns (1976), all organizations are sociotechnical systems, where systems refers to tasks, process and people to carry out day-to-day duties. Organizations that are approaching change and using technology must understand that a "change model" that incorporates sociotechnical perspectives is critical. In addition, the model itself can and should be customized to fit the social network of the organization (Appelbaum, 1997).

Social and technical variables must achieve joint optimization to produce outcomes to accomplish tasks outlined by the organization (Emery \& Trist, 1960). Because technical innovations are placed in social situations, organizational dynamics matter because they affect how technology is adopted and trusted by those in the organization (Clarke, 2006). Emery and Trist go on to say that, analysis of a technical system can produce tasks and interrelation components required to achieve technical functions. In addition, employees must be given a high priority in the organization just as much as the technology and processes to accommodate the change process (Mumford, 2006). The results of social technical design research showed a positive relationship between efficient use of technology to increase productivity and improvement of quality of work life (Mumford, 2006). In order for the technical system to be successful, it relies on how well the social system is able to cope with the requirements. Emery and Trist discussed the interdependencies of implementing a technical system. Leavitt (1964) mapped the approach to organizational changes demonstrating the interdependence of each of the 
four areas (see Figure 1). Leavitt also said that while all four areas are impacted any change will impact structure and therefore will impact the motivation, attitudes and trust of those being impacted by the change.

The socio-technical systems approach identifies that social and technical needs must be identified prior to implementation to achieve high productivity and adoption (Cherns, 1976). Herrmann, Loser, and Jahnke (2007) introduced a facilitated systematic intervention communications process, Socio-technical walkthrough (STWT), with employees prior to implementation to facilitate better success of the introduction of technology. Their approach was to "study the relationships and interrelationships between the social and technical parts of any systems". One of the outcomes of that study found that the STWT process lead to sharing knowledge between people before the technology was introduced (Herrmann et al., 2007). In addition, STWT discussed that the way social systems and technology relates is based on the level of communication about how technology is used within an organization (Herrmann et al., 2007).

The implications of this study can help organizations understand the integration of knowledge from stakeholders to further communicate the purpose of the technical system, how it will be used, responsibility to maintain, and what users are tasked to do. Further more the knowledge can not be just distributed, but applied to tasks to generate new knowledge. This will guide how employees carry out tasks, influence decision making, give a foundation for communication and create and environment to share perspective to solve of prevent problems (Herrmann et al., 2007). The purchase and implementation of a vended solution was a task of the UM System CRI committee. The technology it was chosen through a request for proposals (RFP) process at the UM System. The RFP process addressed several high-end needs identified by each 
of the campuses that vended solutions could respond to. However, the design of tools, processes, people, and timing are varying internal controls at each campus. The framework states that the traditional practice is to design the technology together with people in the organization and then further implement. However, in this case the early alert system is a pre-created vendor-based product and could lead to implications of poor adoption and low productivity (Cherns 1976; Emery \& Trist, 1960).

Sociotechnical systems theory can be easily adopted to any organizational situation. The theory remains opens for further application and improvement (Appelbaum, 1997). The socio technical body of literature is the most extensive body of work that explores people involvement and technical applications design (Appelbaum, 1997). While the technology supports an overall need identified at the UM System level, the core components delivered and how tools and processes are implemented may have an impact in the overall adoption and productivity in early alert programming. The processes, tasks, people involved, current structure and new technology must be taken into account and aligned to achieve the best productive outcome.

\section{Readiness for Technology Adoption}

Karp and Fletcher (2014) discussed a new Readiness of Technology Adoption (RTA) Framework. This literature states that as a new student success technology is deployed the likelihood of adoption will increase if readiness meets the flowing criteria: Technology, Organizational, Project, and Motivational Readiness. The RTA framework provides a model to best understand student success technology adoption. The framework provides a model to support institutions that are beginning to implement technology for the first time. However, technology and project readiness alone are "necessary but not sufficient" to achieve technology adoption success (Karp \& Fletcher, 2014, p. 8). 


\begin{tabular}{|c|c|c|}
\hline & Technology & Culture \\
\hline Institution Level & $\begin{array}{l}\text { Technological Readiness } \\
\text { - IT system maturity } \\
\text { - IT system stability } \\
\text { - Compatibility of new and existing IT } \\
\text { - Current patterns of IT use } \\
\text { - Past experience with IT implementation }\end{array}$ & $\begin{array}{l}\text { Organizational Readiness } \\
\text { - Clarity of mission } \\
\text { - Communication } \\
\text { - Decision-making process } \\
\text { - Openness to change }\end{array}$ \\
\hline Project Level & $\begin{array}{l}\text { Project Readiness } \\
\text { - Administrative and technical resources } \\
\text { - Training } \\
\text { - Ongoing support } \\
\text { - Incentives }\end{array}$ & $\begin{array}{l}\text { Motivational Readiness } \\
\text { - Need for reform } \\
\text { - Vision of benefits } \\
\text { - Perception of functioning }\end{array}$ \\
\hline
\end{tabular}

Figure 2. Karp and Fletcher (2014) Readiness for Technology Adoption Framework The RTA framework defines cultures and pre-existing attributes and behaviors that make up the group or organization. The RTA framework assumes that all institutions have underlying behaviors and micro cultures that influence how likely users will embrace change. This framework provides a focus to ensure that "technology-based reform leads to end user adoption and changed practice" (p.13). Karp and Fletcher (2014) also discussed that adoption is not solely about the technology but the college's organization will influence how people use the new student success technology to improve their everyday practices. This provides and understanding how each campus's users are using the technology and areas for further support. Organizational readiness and motivational readiness are the important because in order to truly adopt the technology it needs to be adopted in the users' daily workflow (Karp \& Fletcher, 2014). These two readiness areas are significant to the study because it provides a frame for further understanding and resources needed to support ongoing implementation and adoption efforts. While a college may be technically ready, if the culture of the organization is not accounted for they will be less likely to be successful with student success technology adoption (Karp \& 
Fletcher, 2014). For this reason, the purpose of this literature review all four readiness areas will be discussed, but there will be a specific focus on motivational and organizational readiness to support the literature review.

Four Readiness Areas. The technological readiness in the RTA framework focuses on the college level characteristics that may affect the new technology (Karp \& Fletcher, 2014). Karp and Fletcher (2014) discussed that the literature indicates that "mature IT systems facilitates end-user adoption" (p. 4). The increased compatibility of systems to integrate with the new system will aid users in adopting a new system. Readiness to move forward with the project and having sufficient tools available to support the project is another component to the RTA framework. The literature discussed that having a project manager and dedicated staff to support implementation is critical (Karp \& Fletcher, 2014). Training and ongoing support is also critical to provide designated time to training users and provide support to help users resolve issues as they start using the new technology. Organizational readiness is also important because colleges that have clearer missions are more likely to understand how new technology can improve their daily workflows. By creating a culture that is included in the decision making process it will create momentum and will increase adoption efforts. Karp and Fletcher (2014) discussed that organizations are complex social structures and openness to change depends not only on leadership, but on the users in the organization that will adopt the technology. The RTA framework discussed that motivational readiness is "determined by the vision users have of the technology and how they will use it in comparisons with current practices along with their motivation to move beyond the often-comfortable status quo" (p. 10). If users have a clear understanding of why technology is needed and understand the vision of benefits with the current 
technology, it may provide an increased opportunity for change. The literature described provides a sound framework to guide the design of the study.

Technological Readiness. The technological readiness in the RTA framework focuses on the college level characteristics that may affect the new technology (Karp \& Fletcher, 2014). This includes the following; Informational Technology (IT) system maturity and stability, compatibility of new and existing IT, and past experience with implementation (see Figure 2). Karp \& Fletcher (2014) discussed that the literature indicates that "mature IT systems facilitates end-user adoption" (p. 4). The increased compatibility of systems to integrate with the new system will aid users in adopting a new system. Lastly, past experience with IT implementation also plays a role in readiness to adopt a new technology. If an institution has past experience with technical implementations they are more likely to have a smooth transition that will help with future efforts.

Project Readiness. Readiness to move forward with the project and have sufficient tools available to support the project are components to the RTA framework. This refers to the administrative and technical resources, training, ongoing support, and incentives (see Figure 2). The literature discussed that having a project manager and dedicated staff to support implementation is critical (Karp \& Fletcher, 2014). Training and ongoing support is also critical to provide designated time to training users and provide support to help users resolve issues as they start using the new technology. Incentives are also key because they provide the encouragement to new users to utilize a new technology (Karp \& Fletcher, 2014).

Organizational Readiness. The RTA framework supports four components that contribute to organizational readiness; clarity of mission, communication, decision-making process, and openness to change (see Figure 2). College that have clearer missions are more 
likely to understand how new technology can improve their daily workflows. In addition, communication is critical to organizational readiness because plans for adoption must be clearly communicated to stakeholders vertically and laterally (Karp \& Fletcher, 2014), meaning top down to leadership, but also to advisors, coordinators, and support staff. By creating a culture that is included in the decision making process, it will create momentum and will increase adoption efforts. Karp and Fletcher (2014) discussed that organizations are complex social structures and openness to change depends not only on leadership, but on the users that will adopt the technology.

Motivational Readiness. The literature discussed that motivational readiness is "determined by the vision users have of the technology and how they will use it in comparisons with current practices along with their motivation to move beyond the often-comfortable status quo" (Karp \& Fletcher, 2014, p. 10). Three elements of motivational readiness are: need, vision of benefits, and perception of functioning (see Figure 2). Need describes how the new technology will address and fill the needs of users. If users have a clear understanding of why technology is needed and understand the vision of benefits with the current technology it may provide an increased opportunity for change. The specific benefits are important to share with users so that they can understand benefits for their day-to-day work (Karp \& Fletcher, 2014). Lastly, the perception of the current technology and new technology to be adopted is more likely to be adopted when users see the benefits in improving their daily efforts. This will result in increased confidence in using early alert and can solidify adoption of a new student success technology at a 4-year public institution.

The adoption of the early alert technology alone presents a challenge and the RTA framework surrounding student success technology adoptions provides a framework to better 
understand challenges of adoption at a 4-year research institution. Rather than choosing a framework from industry this is the best framework that represents higher education technology adoption readiness. The RTA framework has undergone primary validation work and additional validation work is underway. However, while the tool is not a final predictor it is a tool to help college level leadership help guide conversations and next steps for implementation to guide adoption efforts.

\section{Conclusion}

Leavitt's (1964) model, socio-technical systems theory and technology readiness are critical bodies of literature to future support understanding the critical elements and implications of implementing technology. The literature demonstrated key components of how an organization will be able evaluate their implementation approach and challenges for a new student success technology. The literature discussed how to prepare and assess readiness to align project, organizational, technical and motivation readiness amongst those needed to support and engage in the early alert process. While there is a gap in literature surrounding implementation models for student success technologies the literature provided insights of key retention factors, technical and human factors to consider. The implementation of student success technologies are new and evolving practices and the literature synthesized provides a step in better understanding organizational implications to adopting technology at 4-year public institutions. 


\section{SECTION FOUR:}

\section{CONTRIBUTION TO PRACTICE}

\section{Executive Summary}

\section{University of Missouri System-Implementation of Early Alert Warning Systems at 4-year Public Institutions}

This is summited to the UM System Academic Affairs office. I wish to share the UM System case study of early alert with UM System and campus leadership to learn about early alert findings and implications that are essential to further support early alert workflows and adoption across all campuses.

With increased pressures on student retention and graduation, implementation of student success technologies were identified as mission critical tools to support student success at the University of Missouri (UM) System. The UM System has a central governance structure and the Academic and Student Administrative Systems Oversight Committee (ASASOC) supports the central strategic technology initiatives with the four campuses. In spring 2013, the ASASOC proposed a "comprehensive approach to use common advising software tools, tailoring software to meet both campus and system needs, implementation workshops, and creating conditions necessary to improve student retention and ultimately graduation" (p. 5). To execute and support the vision ASASOC appointed the, Comprehensive Retention Initiative (CRI), a task force of core leadership from each of the four campuses to identify technologies. This new initiative was a top down approach from the UM System to each of the four campuses to support retention and graduation success rates. The UM System wanted the four campuses to purchase the same solutions and did not assess the readiness or need, thus adding another layer of complexity to the effort. The University of Missouri System purchased early Alert technology, Hobson's Starfish, in spring 2014.

\section{Framework \& Purpose}

The framework for this study is Leavitt's (1964) Diamond, Integrated Approach to Change, which was based on Socio-Technical Systems Design (Cherns 1976; Emery \& Trist, 1960). It evolved from social technical theory to give a broader approach to understand the relationships between people, task, structure and technology. The model demonstrates an interdependency when change takes place in one area all areas must be evaluated to understand the impact on each of the components. This framework was used to provide a lens on socio-technical perspective to understand the relationship between leadership, users (faculty and staff), technology, and the organization when implementing a campus wide early alert program facilitated by new technology. This will provide administrators and practitioners with strategic approaches to tackle future early alert implementation and adoption challenges at four-year public universities when implementing student success technologies.

\section{Methods}

I conducted six interviews and six focus groups with 42 participants who were users of the early alert technology across the UM System. Interviews were conducted with the early alert project manager at each campus to understand implementation and the intended functions of early alert. Focus groups included leadership, academic advisors, instructors, and student service 
coordinators. The focus group participants were critical to best understand perception of how student success initiatives impact their roles and how technology, individuals, and the campus organization influenced the adoption of a campus early alert program. Since each participant is responsible for coordinating different aspects of early alert, it was informative to understand their experiences and perspectives.

\section{Answers to Research Questions}

RQ1: What is/are the organizational change(s) needed to support the implementation of early alert at each campus with in a university system? Derived sub questions:

1. What campus services and offices are currently the key contributors to the implementation of early alert on each campus? (Conversely, which are missing or should be involved to contribute to a successful adoption/implementation of the system?)

A critical starting point to understand early alert systems are the key stakeholders involved in implementation (Leadership, IT and Functional Support) and participation (Flag Raisers \& Responders) in the early alert process (see tables below). Some campuses have distant relationships while others have a strong collaboration. For example, UMKC shared that in order to get Information Technology support they need to submit a ticket and it may take up to a week to get a response. Whereas at MU, the SIS programmer has the Starfish system integrated into his duties to expedite daily requests. Technology support plays a critical role in having a seamless experience for users, thus supporting consistent adoption. In addition, academic advisors, residential life, financial aid, counseling centers, and student health can also play a key role in identifying critical issues and providing student support. Leadership from senior academic administrations, deans, and department chairs is needed to engage with early alert (Greenfield, Keup, \& Gardner, 2013). Critical players are Information Technology, Learning Management System and data programming support to support state feeds, integrations, and troubleshooting. While each campus has similar resources noted below, the partnership levels and access to resources may vary.

\begin{tabular}{|l|l|l|l|}
\hline \multicolumn{4}{|c|}{ Leadership, IT and Functional Support } \\
\hline \multicolumn{1}{|c|}{ MU } & \multicolumn{1}{c|}{ UMKC } & \multicolumn{1}{c|}{ UMSL } & \multicolumn{1}{c|}{ S\&T } \\
\hline Information & Information & Information & Information \\
Technology & Technology & Technology & Technology \\
\hline Student & Student & Student & Student \\
Information & Information & Information & Information \\
Systems & Systems & Systems & Systems \\
\hline LMS Support & University & Undergraduate & Undergraduate \\
(ET@MO) & College & Studies & Studies \\
\hline Undergraduate & Institutional & Institutional & Institutional \\
Studies & Research & Research & Research \\
\hline & Registrar & & \\
\hline
\end{tabular}


Each campus had faculty involvement and academic advising unit involvement. However, every campus shared that there are various levels of adoption with in faculty groups and academic advising. While all campuses shared that they had champions of the tools they were still working on critical faculty (high enrollment, high DFW courses) and critical advising units to "get on board" Without exception, every campus shared that staff advising had higher adoption rates than faculty advising. Users shared that these varying levels buy-in contributes to the inconsistencies in the process and communication of workflows, resulting in a lesspositive impact.

In addition, each campus has various academic supports included. MU for example has residential life included where the other campuses do not. UMSL has Student Affairs integrated into their workflows where the other campus do not.

\begin{tabular}{|l|l|l|l|}
\hline \multicolumn{4}{|c|}{ Flag Raisers \& Responders } \\
\hline MU & \multicolumn{1}{|c|}{ UMKC } & \multicolumn{1}{c|}{ UMSL } & S\&T \\
\hline Faculty & Faculty & Faculty & Faculty \\
\hline $\begin{array}{l}\text { Academic } \\
\text { Advising Units }\end{array}$ & $\begin{array}{l}\text { Academic } \\
\text { Advising Units }\end{array}$ & $\begin{array}{l}\text { Academic } \\
\text { Advising Units }\end{array}$ & $\begin{array}{l}\text { Academic } \\
\text { Advising Units }\end{array}$ \\
\hline \multirow{4}{*}{$\begin{array}{l}\text { Academic } \\
\text { Retention Services }\end{array}$} & University & Academic & \\
Athletics & College & Setention & \\
\hline Learning Center & & Athletics & Graduate Studies \\
\hline & & Honors College & \\
Residential Life & & Office of & \\
\hline & & Academic & \\
& & Integrity & \\
\hline & & Office of Student & \\
& & Affairs & \\
\hline
\end{tabular}

2. What are the current tasks (work processes) of faculty and staff when using the early alert system? (And which tasks are missing or should be integrated in the EA system to contribute to student success?)

The current tasks of early alert are as follows;

a. Faculty- Flag raising, documenting notes in the system (flag comments), finding flag information and flag clearing.

b. Academic Advisors/Student Services- Identification of students with flags, perform timely outreach functions (email, phone, text), document notes in the 
system (flag comments), clear flag, and close loop with faculty informing when intervention occurs.

c. While all tasks between groups are present at each campus, the timeliness of flag raising by faculty and outreach to flags are inconsistent. Users expressed that while they felt that early alert is "a good program in theory" they did not feel that that they has the capacity to carry out raising and/or outreach in addition to their current instructor or advising loads. Users also showed a disconnect in understanding who was responsible for different tasks in the system. Users referred to "unclear expectations". It is important to note that units within each campus are strong in completing tasks, but the inconsistencies and perceived complexities of workflows across the whole campus creates a lack of understanding, trust, and dependability on the system.

3. How does the perception of faculty/staff about student success/performance influence the use/adoption of early alert system?

a. Faculty and staff identified student success as navigating campus, retention, graduation rates, career readiness, changing major, overcoming obstacles, and transferring institutions.

b. Faculty and staff perceived student success as the outcome that was related to their specific role on campus. For example, instructors viewed success as succeed in a course and advisors shared that student success was about graduating and finding a job.

c. Faculty and staff reported that their perceived or understood role in student success fell into the category of "other duties as assigned" or something that they only needed to offer "a good faith effort," but it was not integrated into daily workflows or expectations.

d. Faculty and staff had a positive response to the concept of early alert as a student success best practice. However, results indicated they had a need for campus leadership to share more data, to demonstrate the impact and clearly communicate their expectations. It would help if campus leadership also expanded the capacity of the campus to support the early alert efforts.

e. Faculty and staff were unclear how their roles contribute to student success which in turn impacted how they used the technology. As a result each used the technology based upon their own personal needs rather than using technology as the institution intended to improve student success. 


\section{Recommendations \& Connection to Practice}

External and internal communications that clearly illustrate the overarching vision and specific goals as well as the expectations for faculty and staff involved to effectively use the tools to enhance the effectiveness of the early alert at the system level and at each campus. Insufficient and unclear communication was a theme that came up across all focus groups at each campus. It was clear that there was inconsistent understanding of the intended use as well as of the expectations of the outcome information based upon what was stated by focus group participants and observed in the use and management of the different flags by faculty and staff. One example of this is, users do not add data into the Early Alert system (flag raising or flag clearing) because they are not "aware" that another person on the workflow needs the information to continue their work. With awareness of the interfunctionality of the tools and better communications embedded into EA systems and external communications, usage and performance would improve because the sharing of information is an unnatural act (Davenport, 2007)

To develop recommendations that are based upon actual user's behavior and tied to specific practices, I sought to understand which campus services were key contributors to support early alert, what the tasks of the users were, what user's perceptions of student success were, and the relationship between technology and people. I learned about each campus's organizational and early alert structures, past early alert systems, resources, communications, successes, and challenges. This was important because the relationships of task, people, structure, and technology are interrelated. If there is a change in one component (e.g., technology) the other three components must be addressed (Leavitt, 1964). Below are the findings of each of the core areas of that contribute to successful organizational change as they relate to early alert. The recommendations are presented to support the UM System and each campus in their efforts to leverage tools more effectively. The findings address: which campus services are key contributors, identification of tasks of users, establishment and communication of leadership expectations, documentation of resource allocation, technology, and finally the outcomes data and assessment.

\section{Leadership Support}

The findings indicated that users felt a lack of clear communication from leadership regarding their expectations for early alert. While each campus had leadership involved during implementation, expectations varied across each campus. Participants at each campus felt that there was not a campus policy or documented expectation of the strategic goals of the early alert system and participants experienced a disconnect with their roles due to a lack of communication about the expectations for users. Grudin (1988) discussed that the implementation may not be successful because decision makers have a lack of understanding that "extra work will be required of others" (p. 86). They shared feeling that leadership plays a vital role to define the strategic direction, communication of expectations, and providing support of ongoing operational needs. Going forward, leadership at the UM System level and at each campus is encouraged to demonstrate and communicate clear support of EA by first requiring that early alert be tied into any strategic plans and by directing that UM System and each campus to develop a Student Success Council to evaluate the current status and determine the best way to scale-up the current solution. In addition, they need to provide the necessary resources to follow through on the recommendations so as to achieve the goals laid out in the strategic plans.

Strategic Planning. Early alert should be integrated into system and campus strategic planning processes and documented to enhance understanding of the vision and specific goals. 
Ideally, a readiness assessment would have been conducted prior to implementation to anticipate perceive obstacles to create an effective plan (Karp \& Fletcher, 2016). Even though each campus are past implementation phases, Karp and Fletchers work should be used as an evaluation tool to determine the current status and identify next steps. Without incorporating early alert into the global campus plan it may get lost amongst other priorities (Greenfield et al., 2013). In addition, campus leadership should communicate the plans in a transparent way for all users to understand their role in the process.

Student Success Council. A student success council should be established at the UM system level and coordinated with one at each campus level. Establishing councils provides a mechanism for an ongoing feedback loop to support all parties engaging in the system, thus supporting campus and UM System-wide adoption (Greenfield et al., 2013). These councils would be charged with identifying the needs and request the needed support from campus leadership (i.e.: funding, staffing).

\section{Resource Allocation}

The findings indicated that users understood the main purpose of early alert, but the understanding of critical tasks related to their role and implications for student success in relation to the use of technology varied. Faculty and staff identified the term student success as a student successfully navigating campus, retention to the next semester, graduation from the institution, career readiness, changing majors, overcoming obstacles, and/or transferring institutions. However, faculty and staff perceived that campus leadership used the term student success as a short-hand for referring only to retention and graduation initiatives. Academic advisors and members of academic support offices who did not have use of early alert tools specifically in their job duties reported student success as falling into their "other duties as assigned" or a that they did not need to do more than make a "good faith effort" effort to fulfill their responsibilities Faculty also shared that they too could meet the leadership expectations as long as they made "a good faith effort to participate." Faculty and staff had connected early alert as a student success practice; however, there was a disconnect with understanding how their role in student success fit into to the use of the technology and leveraging of the functional elements that early alert supports. For example, faculty at S\&T did not understand why they should raise a flag or in some cases give timely feedback when they "could just talk to a student at the end of class." Through focus group discussion advisors were able to share how they integrate information from the faculty to conduct outreach, holistically see all student information, and then use the information to support student success.

Furthermore, depending on the office at each campus, many users shared that use of the early alert system was not formally integrated into their job. For example, UMSL has a Retention Office and MU has a Center for Academic Success and Excellence. In both offices, early alert has been defined as a core process to support students, use of technology was expected, and expectations were communicated to the end users. However, flag responders' usage in other academic support functions (e.g., academic advising) varied throughout each campus. This was common across all campuses, where some units widely adopted the tools while other offices did not fully embrace the tools. Many users expressed that it was another "thing" to add to their plates when they felt that they were overloaded as it was.

Human Resource Expectations \& Staffing. Often organizational technology can fail because it requires that some people may have to do additional work and often those people are not the ones who understand the direct benefit from the technology (Grudin, 1988). 
Identification of an office and and communication about which person(s) are to be responsible (as well as why) are key to effective implementation and coordination of the system (Greenfield et al., 2013).

During implementation, each campus assigned a support person to implementation. MU hired a new full time staff to support Starfish. UMSL hired a coordinator to support all retention software, including Starfish. UMKC and S\&T assigned the project to current staff members at the central campus level to support implementation. UMKC hired a full time staff and S\&T hired a 50\% staff member out of the Registrar's Office after initial implementation. Leadership staff who were present in focus groups expressed a need for more resources to support the ongoing work. In addition, academic advisors expressed a need for more support of the early alert outreach process. They shared that due to capacity of their current advising loads it was difficult to integrate the additional work into their current advising duties.

Findings pointed to the need for additional staffing to support each campus's early alert process. Users on each campus felt the need for more support to implement and sustain the endeavor if the campuses truly wanted to see examples of enhanced student success. Human resource support and evaluation at both the system and campus level are needed for key contributing roles of those involved in the early alert process. UM System level support is needed to support each campus with further implementations and assessment. In order to increase the adoption rate and sustain appropriate growth in the use of the tool's capabilities, each campus needs at least one additional, full-time staff member dedicated to supporting the tool (e.g. dealing with day-to-day issues, questions, etc.) as well as implementing new features and upgrades, providing regular, communication to end users, training new staff and training current staff on new features, as well as helping with student onboarding.

Training. Training is an essential function that should be considered essential and delivered regularly for all users who are core to the early alert processes (i.e., Faculty, Academic Advisors, Financial Aid Advisors, Residential Life Staff, Academic Support Staff) (Greenfield et al., 2013). Workshops should be made available at times where it is convenient for staff and faculty to participate. A training plan should be incorporated into implementation and built into the plan for support and expansion of use. Workshops should also be integrated into campus events to onboard or to scale-up user adoption. Events include: new faculty orientation, departmental meetings, retreats, advisor trainings, and staff meetings.

\section{Technology}

Participants at each campus expressed that often they were overwhelmed with the amount of early-alert tools that they had access to and were unsure what they were supposed to do with the information or when to deploy which piece. For example, one person asked, "Is it informational or is it something I should act on?" Users shared that they were, "afraid they would hit the wrong button, and that they didn't know what flags were systematically applied versus manual." While this was said at all campuses, this was discussed most at UMKC, due to this campus having a large number of system and manual flags in place, thus confusing users on the processes. In addition, users at UMKC shared that the technology was not giving them the whole picture of the student information because it is not shared between divisions, which limits the ability to creating holistic access to those with an academic need to know. UMKC's system design should be reviewed to better equip academic advisors with the capabilities that the system was aimed to support. Lastly, all campuses were overwhelmed with the amount of technology being introduced at the faculty and staff levels. This was expressed the most at MU, with staff 
sharing the need for more integration of all technologies (myZou, MU Connect, Schedule Planner, DARS, Canvas) through more training and communications, as well as having "one place to go" to find all the tools.

\section{Data \& Assessment}

How do we know if it works? This is the ongoing question posed by all campuses. Users expressed a need to be more data informed and shared that access to key data would strongly influence the willingness to accept and use the process for both faculty and staff. An assessment plan needs to be created at the UM System and at each campus. The plan should include operational and outcome data, and be incorporated into the overall implementation planning process (Greenfield et al., 2013). Assessment should also draw from both quantitative and qualitative data. Examples include student, staff, and faculty focus groups; implementation surveys; operational data to show participation; and formative evaluations regarding satisfaction with the technology. Outcome data should also be assessed. Common questions to pose and seek answers to include: What offices are engaging and what offices need further support? What students should be targeted? What outreach processes are most effective? What improvements can be made to current outreach processes? Where should we operationalize new tactics to support student success? What factors demonstrate a positive outcome for students and courses? Do students who participate have a change in academic performance? Is there a relationship between attendance and retention? Not only will the data collection impact the roll-out of new features and updates tools, but it will influence those tasked to use the tools to keep engaging in early alert processes and engage new users.

\section{Conclusion}

In terms of retention and completion, new tools alone do not provide a direct path to success. Tools can always be created to address a multitude of needs, but they will never be truly useful until they are applied with purpose and integrated into business practices. The how of adopting new technology is difficult because human nature provides a simple yet complex barrier to change. The phrase often spoken, "It's the way we always have done things," gets in the way of adopting something new. Firm commitment to process changes must come before technology and it is that commitment that will make or break adoption. The more that is learned about the relationship between people, task, process, and technology, the more awareness will be created to identify what is relevant to problems, which can then be detected prior to or early in the implementation phase. In order for the technical system to be successful, the social system must be able to cope with the requirements (Emery \& Trist, 1960). The findings indicated that adoption from stakeholders across each campus varied. Campuses like UMSL had strong academic support, but also expressed areas for improvement. However, S\&T expressed that faculty adoption was a hurdle to adoption. Faculty members have more autonomy in choosing how and what they do in the realm of advising compared to staff advisers. Other important influencing factors like leadership engagement support from information technology units, and staff member functional support varied across each campus. Developing more consistent buy-in at each campus will provide a sound environment for early alert to address its key function, which is to aid in student persistence and graduation. Results also indicated a lack of understanding of early alert processes at each campus. Having systematic, transparent processes that is successfully communicated to the faculty and staff who are to use it will be key to success. In addition, it was consistently demonstrated that additional human resources were 
needed in addition to more, support for the technology will further enhance the campuses' ability to reach retention and graduation goals set by forth by the UM System and each campus.

\title{
SECTION FIVE:
}

CONTRIBUTION TO SCHOLARSHIP

\begin{abstract}
A University System Approach to Early Alert Implementation - A Multisite Case Study of How People, Task, and Technology Influence Implementation and Adoption.
\end{abstract}

Tina J. Balser 


\begin{abstract}
This multisite case study of academic early alert warning system implementation explored the relationship between leadership, users (faculty and staff), technology, and the organization when implementing a campus wide early alert program facilitated by new technology at a university system in the Midwest. Early alert technology allows faculty and staff to raise academic concerns and outreach to students during the semester. The findings suggested that technology, people, task and structure were core components impacting implementation and adoption of tools. The findings also suggested that clear expectations from leadership, alignment of tasks within job duties, clearly defined processes, resources to support training, and data outcomes are essential to early alert adoption.
\end{abstract}


A University System Approach to Early Alert Implementation - A Multisite Case Study of How People, Task, and Technology Influence Implementation and Adoption.

Students come to college with varying levels of academic preparation that may contribute to their academic success (Bean, 1990). There are academic, motivational, psychosocial and financial factors that can be proactively identified early on to influence students' persistence (Barefoot, 2004). Institutions in the past did not have a way to respond early in the semester to student behavior that contributed to their academic success. This reactive practice to raise academic concerns and outreach to students during the semester is known as early alert. Early alert systems are defined as "a systematic method of recording and communicating student behaviors that contribute to student attrition that can aid in student retention efforts" (Tampke, 2012, p. 524). Campuses from around the United States are adopting new practices supported by technology to reach out to students about academic, financial, social, and health concerns raised by a staff or faculty member that can impact student persistence (Greenfield, Keup, \& Gardner, 2013).

Early alert practices and technology are new and evolving in higher education (Greenfield et al., 2013). In order for early alert to be successful, faculty and academic support areas must participate (Greenfield et al., 2013). The approach must be service-oriented so the student will feel that they can approach the office or person reaching out to them (Tampke, 2009). Many campuses are looking at these types of systems as a strategic solution and investing resources into new tools, but it is critical that there is support regarding practices to support all users involved in the process, particularly those who are unfamiliar with this technology.

The early alert technology enhances real-time reactive capability during the semester to allow instructors to raise flags and for academic support offices to identify and proactively reach 
out to students who are experiencing academic difficulty (Tampke, 2012). Students experiencing academic difficulty can benefit from effective interventions that then improve their chances of being retained (Tampke, 2009). More specifically, "students who do not experience academic success during their first semester of attendance will be less likely to be retained" (Greenfield et al., 2013, p. 179). Therefore, while an early alert system is known to have a positive impact on student success and retention (Tampke, 2009), there are several variables that play a role in user adoption of these early alert systems, including the relationship between technology, individuals, and the organization (Leavitt, 1964). The focus of this study is on the process of how an early alert program is implemented and adopted on four campuses within a university system.

\section{Literature Review}

According to Greenfield, Keup, and Gardner (2013), early alert warning systems (EAWS) are evolving in higher education. Campuses from around the United States are adopting new practices supported by technology to reach out to students about academic, financial, social, and health concerns raised by a staff or faculty member that can impact student persistence (Greenfield et al., 2013). Students come to college with varying levels of academic preparation that may contribute to their academic success (Bean, 1990). There are academic, motivational, psychosocial and financial factors that can be proactively identified early on to influence students' persistence (Barefoot, 2004). The ability to systematically identify students who are experiencing academic difficulty provides an opportunity for institutions to identify students and intervene. (Cuseo, 2006, Greenfield et al. 2013, Tampke 2009). Institutions in the past did not have a way to respond early in the semester to student behavior that contributed to their academic success. However, with these new early alert systems the current practice can be changed to raise concerns and outreach to students during the semester to with the goal to 
positively affect student, faculty, and university level behavior toward improved student success. This reactive practice to raise academic concerns and outreach to students during the semester is known as early alert. While the early alert process itself is proactive to address concerns prior to the end of the term, it is truly a reactive practice because users are reacting to student behaviors during the term. A proactive retention process would occur prior to the start of the term using predictive data sets to identify students that are at risk before ever stepping into a classroom.

Following the studies by Tampke (2009), Cuseo (2006), and Simons (2011) early alert process have evolved in many ways across high education institutions. They started a traditional mid-term check paper based process, where a faculty would fill out an internal form, submit to the dean's office and it would take weeks to get to a dean to reach out and meet with a student (Gardener et al., 2013). In addition, the outreach in earlier years was designed as serviceorientated at all. It was like coming into the principal's office (Tampke, 2009). Recent studies demonstrate that in order for early alert to be successful: a) faculty and academic support areas must participate (Greenfield et al., 2013; Tampke, 2009), b) students should feel that they can approach the office or person who is reaching out (Tampke, 2009), and c) instructors should engage in early alert as a social practice, users may be introduced to the practice and new technology for the first time. Campuses are looking at these types of systems as a strategic solution and investing resources into new tools, but it is critical that there is support of all users (students, faculty, staff, and leadership) involved in the process.

Early alert systems are defined as "a systematic method of recording and communicating student behaviors that contribute to student attrition that can aid in student retention efforts" (Tampke, 2012, p. 524). Retention of students is a constant topic of conversation and concern at many universities (Tampke, 2009). While the early alert technology is new to higher education, 
the process of identifying students that may be experiencing academic difficulty is not a new, but how concerns are reported may change with new technology. The early alert technology enhances a real-time reactive capability during the semester to allow instructors to raise flags and academic support offices to identify students who are experiencing academic difficulty and proactively reach out (Tampke, 2012). Students experiencing academic difficulty can benefit from effective interventions that then improve their chances of being retained (Tampke, 2009). More specifically, "students who do not experience academic success during their first semester of attendance will be less likely to be retained" (Greenfield et al., 2013, p. 179). While an early alert system is known to have a positive impact on student success and retention (Tampke, 2009), there are several variables that play a role in why user adoption of these early alert systems, including the relationship between technology, individuals, and the organization.

Simons (2011) found that $68 \%$ of early alert systems have only been in existence for five or fewer years. In contrast, Greenfield et al. (2013) introduced organizational and implementation concerns, and student impacts as an additional resource. The literature also discussed how to utilize assessment, engage faculty and staff, and further advance the early alert system once it is implemented. As the literature stated, institutions are new to implementation and the early alert systems are new technologies and because of this there is not a strong conceptual framework for researchers to create a better understanding for implementation of early alert systems (Simons, 2011).

The socio-technical systems approach identifies that social and technical needs must be identified prior to implementation to achieve high productivity and adoption (Cherns, 1976). University of Missouri System wanted to implement a menu of student success technologies to support retention and graduation. One of the technology requirements was to support a campus 
wide academic early alert system at all four UM system campuses. The UM system purchased Starfish, an academic early alert system, in spring 2014. The technology was chosen through a request for proposals (RFP) process at the UM System. The RFP process addressed several highend needs identified by each of the campuses that vended solutions could respond to. The Starfish system has gone through a variety of implementation phases at each of the UM campuses: the University of Missouri, University of Missouri-St. Louis, University of MissouriKansas City, and Missouri Science and Technology. Each campus had its own implementation plan for the design of the early alert technology, faculty onboarding, outreach and intervention plans, and student communications. Each campus identified core leadership and users to support the implementation and adoption. The design of tools, processes, people, and timing are varying internal controls at each campus. The traditional practice to design the technology first and then put people into it leads to poor adoption and low productivity (Cherns 1976; Emery \& Trist, 1960). While the technology supports an overall need identified at the UM System level, the design of tools, policies, processes and overall campus coordination may have an impact in the overall adoption and productivity in early alert programming. The processes/tasks, people involved, current structure and new technology must be taken into account and aligned to achieve the best productive outcome.

The framework for this study is Leavitt's (1964) Diamond, Integrated Approach to Change, which was based on Socio-Technical Systems Design (Cherns 1976; Emery \& Trist, 1960). This framework offers a socio-technical perspective to understand how people are central to technical innovations, and to understand how people are interrelated with technology structure, and tasks to impact organizational change. Socio-technical approaches to understanding organizational change have been studied and applied in a variety of fields such as 
Organizational Research, Business Research (e.g., knowledge management (Nonaka \& Takeuchi, 1995) and in Computer Science and Informatics such as Computer-Support Cooperative Work (CSCW) (Grudin, 1988), and healthcare (Ackerman, Prilla, Stary, Herrmann \& Goggins, 2018). While socio-technical approaches have also been applied in higher education (Adams \& Ivanov, 2015; Pasquini \& Evangelopoulos, 2017), this study introduces a new perspective to uncover the user experience of an early alert system and introduces a new perspective to understand the variables that play a role in implementation and adoption of early alert systems.

Socio-technical theory focused on the intersection between people and technology. Leavitt's (1964) model provides a deeper multi-dimensional framework to best understand how people, task, structure, and technology intersect when change takes place within an organization. (see Figure 1). The organizational change in this study is the implementation of early alert technology that spurs a review of tasks, process, and roles that people provide across the organization. Each of the four areas in the model (people, task, structure, and technology) are interdependent of one another, meaning that when change takes place in one area, all areas must be evaluated to understand the impact on each of the components. The key to a successful implementation of change is to find the balance that satisfies all four components.

The four areas of Leavitt's (1964) model—people, task, structure, and technology—must be accounted for when implementing a new technology (see figure 1). The technology alone cannot produce a sustainable change. People, task and structure of the organization all must be evaluated to achieve the desired outcome of what the technology is aimed to support. To more thoroughly understand the technical and social relationship, the dynamics and between technology, people, tasks, and structure are essential to understand the influences to early alert 
system adoption. For example, to formulate a change strategy when implementing a new early alert technology, all for components must be considered. The catalyst for change in this study is the early alert technology. If the technology changes, as Leavitt's (1964) model illustrates, there will be an impact on people: flag raisers (faculty) and flag responders (academic advisors and student services staff); task: processes that were once done on paper, in a previous system, or a new process; structure: centralized or decentralized, communication flow, and workflow. Leavitt (1964) argues that while all four areas are impacted it will impact structure and therefore will impact the motivation, attitudes and trust of those being impacted by the change.

\section{Research Question}

What are the organizational changes needed to support the implementation of early alert at each campus within a university system?

\section{Methodology}

I conducted a multisite case study. This approach was relevant to find a deeper understanding of the interrelationships that technology, individuals, and the campus organization play when implementing a new initiative at each campus. The research question was initially selected were modified as new issues were found and constantly evaluated throughout the study (Stake, 1995). Each institution shares common characteristics of implementing a common academic early alert system, but each institution has unique leadership, users, and organizational design. The multiple cases included provided more a more robust and compelling interpretation to enhance the external validity of the findings (Merriam, 2009).

\section{The Setting and Participants}

The setting for the research took place at all four UM system institutions in Missouri: University of Missouri (Columbia), University of Missouri--St. Louis, University of Missouri-- 
Kansas City, and Missouri Science and Technology. The University of Missouri (MU) was established in 1839 as teaching and research driven institution (University of Missouri is referring only to Columbia campus). The University of Missouri System (UM System) is a higher education system with four campuses in the state of Missouri located in Columbia, Rolla, St. Louis, and Kansas City. In 1870, a University of Missouri campus was established in Rolla, Missouri. The University of Missouri campuses in St. Louis and Kansas City were last to join in 1963 completing the four campus system. Today, the UM System has 77,000 students, health care and extension offices in every county in the state of Missouri (University of Missouri System, 2017).

To start the data collection process, I sent out a recruitment email to each campus's early project manager and scheduled phone interviews. A formal agreement was negotiated between each early alert manager and myself prior to conducting the on-campus study (Stake, 1995). Preliminary access to participants was discussed along with negotiating a plan of action to conduct interviews with project managers and focus groups with flag raisers, flag responders and leadership at each campus. I worked with each early alert manager to identify specific stakeholders for the focus groups that related to institutional conditions and participated in the early alert process (Kuh, Kinzie, Buckley, Bridges, \& Hayek, 2006), which included faculty and staff representing first year experience, financial aid, academic support, peer support, and retention services.

There are three core roles in the early alert process; flag raisers, flag responders, and students. Students were not included in the research questions as a part of this study. The focus was to have an organizational perspective on the institutional staff and faculty involved. Members identified as flag raisers included tenure tract and adjunct faculty instructors that have 
participated in early alert. Members identified as flag responders were academic advisors, department support staff, retention services staff, registrar staff, and first year experience advisors who monitor, provide outreach, and meet with students. Once key actors were identified in each area at each institution, I emailed all proposed participants inviting them to participate in the study at their respective campus. Consent documents to participate in the focus groups were given to gain written consent of the stakeholders and included that participants could choose to withdraw their participation from the study at any time (Stake, 1995). Focus groups were videotaped and lasted 60-90 minutes.

\section{Methods}

The study was guided by the following research question: How does the implementation of an early alert program influence the relationship of technology, individuals, and the campus organization at a university system? The question was posed to understand the relationship between people, task, structure, and technology to help practitioners who are exploring student success technologies to better understand implications, challenges and approaches to support implementation and user adoption. Six interviews and six focus groups were conducted with key stakeholders involved in the early alert implementation at each institution. Four interviews were conducted with each campus's project manager to best understand the organizational structure of each UM System campus early alert program, approach in implementation, and populations targeted through the use of the early alert tools. Two additional interviews were conducted with participants from UMSL who were unable to attend the focus group. The information that I gained from the early alert project manager was used to design focus group questions, reduce personal bias, and ask more in depth and probing questions to draw out a deeper understanding from participants (Merriam, 2009). In addition, the UM System objectives contributed the focus 
group questions to understand implementation and how buy-in decisions were influences to best understand if the aim and the outcome were consistent. The interview and focus group questions were developed from, CRI documentation, project manager feedback, and Socio-Technical Systems Theory Intervention Questions (Appelbaum, 1997) and Readiness of Technology Adoption Self-Assessment (Karp \& Fletcher, 2014).

Next, six focus groups were conducted to understand the intersection of multiple perspectives from all users engaging in the raising of flags and outreach functions of early alert. Prior to the start of the focus group, participants were asked to fill out a short questionnaire to identify their name, role at their institution, role in early alert implementation and programming, and special populations of students who they target though the use of early alert flags. During and after the focus group session, I took notes of observations and themes that emerged during the focus group.

UMSL and S\&T had one focus group and UMKC and MU each had two groups. Each member of the focus groups brought a different perspective and campus experience. Focus groups included leadership, academic advisors, instructors and student service coordinators. Focus group participants were critical to best understand how the UM System decision affects early alert adoption, how their perception of student success impacts their role, and how technology, individuals, and the campus organization influence the adoption of a campus early alert program. Focus group questions were designed and arranged by hypothetical, devil's advocate, ideal position, and interpretive questions (Merriam, 2009). I followed a semistructured interview protocol to understand the participant's viewpoint (Merriam, 2009). 


\section{Data Analysis}

The process of data analysis includes interpretation and defining the relationship between concepts (Stake, 1995). I applied holistic multiple case study design that focused on the influence of early alert implementation by exploring the experiences of flag raisers and flag responders (Yin, 2009). Finally, the specific methods interviews, focus groups, and document analysis provided a collection of data that addressed the research questions and highlighted the participants experience (Creswell, 2013).

I used direct interpretation and categorical aggregation processes simultaneously to find direct meaning and categorize similar instances found during interviews and focus groups (Stake, 1995). Then I examined the qualitative data through coding of observation field notes, six participant interview transcripts, and six focus group transcripts (Emerson, Fritz \& Shaw, 2011). Coding is the process of making notations next to important information that could be relevant to answering research questions (Merriam, 2009). While reading qualitative texts, I coded all data with an open coding method to further interpret data and reflect on meaning. This allowed me to identify reoccurring patterns across the data to answer the research questions. I grouped the coded data into Leavitt's (1964) four categories that illustrate the relationship between variables findings as they related to early alert implementation: structure, task, people, and technology. During the data analysis, I continuously reviewed the coding process. As I coded each institution's set of data, I created consistent codes and categories to identify groupings of data that responded to my research questions (Merriam, 2009). I identified themes and categories and merged these into a master list to support the research questions (Creswell, 2013). Lastly, I reviewed the data by themes and patterns by respondent type, campus responses, and overall across the system to compare responses. 
As themes emerged from focus groups, I evaluated the responses using respondent validation (Merriam, 2009). This gave me the opportunity to go back to the participants, validate the responses, rule out misinterpretation, and identify any bias. In addition, I used a data source triangulation method to examine if the case remained the same at each campus. I triangulated findings though multiple data sources. Sources included: interview transcripts data, focus group transcript data, CRI documentation, and support of an external validator. Though the data analysis process I looked for frequent themes to respond to the research questions across campuses to identify answers to the research questions for each institution and across the UM System. I also identified similar responses by flag raisers and flag responders to understand similarities across institutions and differing responses by person type.

\section{Findings}

I identified four themes from the data that address the research question: How does the implementation of an early alert program influence the relationship of technology, individuals, and the campus organization at a university system? The four themes are: technology, people, task, and structure. The research findings are categorized by themes based on six interviews and six focus groups from four institutions. The term users refers to both staff and faculty perspectives.

\section{Technology}

Technology has been the driving factor of change. Each campus had a different readiness to adopt new technology that was expressed by leadership, faculty, and advisors. UMSL, UMKC, and S\&T each has previous early alert technologies. Some were homegrown and others had a different vendor. Users expressed that it was just another technology that they were moving towards and they were replicating the same process as before, but in a new technology. 
Others shared that a new technology was a "catalyst for change." There was evidence at each campus to suggest there was not adequate ongoing IT and functional support.

I think we need to do a better job of as a university doing more of our technology onboarding. It could be advisor training, faculty orientations, etc. (UMKC, Leadership) People try to use it and then it doesn't work in the way they expected it to so they were,

they're done with it. Like not wanting to use it anymore. (S\&T, Academic Advisor, Flag Responder)

Users felt that because there were so many technology shifts happening all at once "technology fatigue" was impeding adoption of the system. In addition to new technology, users felt that implementation was very technology driven, less process driven, and were very intimidated by the technology. Users also asked "what does this have to do with student success?" Users expressed a need to understand how the technology supports their work versus additional layers of work; however, users identified that technology expedited their day-to-day processes.

The system supports a lot of efficiencies that I would have had to do in a paper-based way. (UMKC, Academic Advisor, Flag Responder)

It created efficiencies in appointment scheduling and identifying students that were "flagged" as having and academic concern by and instructor.

\section{People}

People are at the core of technology adoption. Users felt that while they felt that early alert in theory is a good practice they did not feel that they had capacity to carry out early alert raising and/or outreach in addition to their current instructor and advising loads. Users also felt that there was variations in faculty and staff buy-in that impedes that ability to timely support 
students. Faculty shared that they were not required, but strongly encouraged. While some staff shared that it is required of their job, others did not.

What is the requirement for us to continue doing it [Early Alert Flag Raising and

Responding] if someone isn't requiring us or measuring it in a performance based way?

(MU, Faculty, Flag Responder)

Faculty identified that it was each faculty member's purview on how and when tools were used. Users shared that faculty and staff turnover impacts getting new users onboard with existing structures. Users expressed various views on student success and their role. Users shared that student success is retention, graduation, changing majors, or leaving college. Users shared that their role in student success was unclear by campus administration. Users also shared that they felt that campus culture affects how others will adopt early alert.

\section{Task}

Users felt that expectations at each campus is not clear to reach adoption needed to sustain early alert needs. Users felt that early alert processes are complex and unclear.

It gets complicated when not everyone is using it in the same way. (MU, Academic Advisor, Flag Responder)

Everyone uses the system in different capacities based on what they need from it, not what the institution is asking them to do with it. (UMSL, Leadership Member)

As a faculty member, I am unsure what happens with the flags that I raise. Some get answered, but unsure why they all don't. (UMKC, Instructor, Flag Raiser)

I used it because I see the value not because someone told me I had too. (MU, Instructor, Flag Raiser) 
Users felt that the task of raising flags and outreach to students with flags were "other duties as assigned" and expressed as "a good faith effort" and not required as a part of their job specific duties.

\section{Structure}

Each campus has different support structures in place to coordinate efforts. Users felt that the decentralized nature of the campus and departments with competing priorities took away from a campus wide coordinated effort.

The car is going but no one is behind the wheel. (S\&T, Instructor, Flag Raiser)

I think we are at a point we're okay it's here; [Early Alert] is here to stay. We are all using it. How do we want this to look institutionally for us? So everybody is clear on what their role is? They get credit for the work that they do. The right people are at the table at the right time. So we're all kind of marching together knowing what we're all doing. That is the idea right? (UMKC, Instructor, Flag Raiser)

Users expressed that there is various leadership buy-in on all levels. Users indicated that there is a lack of policy around tools, process, and people involved. Lastly, users expressed a need for structured communications about data outcomes, processes, and systematic updates and changes to the system.

Having data to show the impact will drive faculty to be more engaged. (MU, Instructor, Flag Raiser)

How do we (faculty and academic advisors) know if early alert is working? (UMSL, Academic Advisor and Instructor, Flag Raiser \& Flag Responder)

Data was a core element expressed at all four campuses and users were eager to learn about the student outcomes of early alert usage to understand if the work is "worth it." 


\section{Recommendations}

I reviewed the themes and specific findings from each category. Based on findings and the interdependency of the four variables discussed I have the following recommendations to support institutions conducting this work. The element of communication is included in the structural component of Leavitt's (1964) model. However, I found that communication was a central theme throughout all of the findings during interviews and focus groups. One example of this is users don't add data into the Early Alert system (flag raising or flag clearing) because they are not "aware" that another person on the workflow needs the information to continue their work. With awareness tools and better communications embedded into EA systems and external communications, it would improve the usage and performance because the sharing of information is an unnatural act (Davenport, 2007). Thus, a new contribution to Leavitt's model (see Figure 2). Ongoing communications with faculty, staff, and students is the central factor to deploying and effective early alert system (Greenfield et al., 2013).

\section{Leadership Support}

The findings indicated that users felt a disconnect of leadership communicating clear workflows and expectations in a holistic way. Participants at each campus felt that there was not a campus policy or expectation to understand the strategic direction of early alert and the expectations for users. Grudin (1988) discussed that the implementation may not be successful because decision makers have a lack of understanding that "extra work will be required of others" (p. 86). They shared that they wanted more of a leadership presence. Leadership plays a vital role to define the strategic direction, communication of expectations, and support of ongoing operational needs. Leadership at the UM System level and 
at each campus is encouraged to incorporate early alert into strategic planning and develop a Student Success Council at the UM System and campus levels to evaluate and scale the current solution.

Strategic Planning. Early alert should be integrated into system and campus strategic planning processes. A readiness assessment should be conducted prior to implementation to anticipate perceive obstacles to create an effective plan (Karp \& Fletcher, 2014). Without incorporating early alert into the global campus plan it may get lost amongst other priorities (Greenfield et al., 2013). In addition, the plans should be communicated by campus leadership in a transparent way for all parties to understand their role in the process.

Student Success Council. A student success council should be established at the UM system level and campus level. Establishing a council provides a mechanism for an ongoing feedback loop to support all parties engaging in the system, thus supporting campus adoption (Greenfield et al., 2013). The council would be charged with supporting ongoing needs, identifying key contributors currently not involved in early alert, scaling solutions through the use of early alert technology, and effectivity communicating best practices to users.

\section{Resource Allocation}

The findings indicated that users understood the purpose of early alert, but the understanding of critical tasks related to their role and implications for student success in relation to the use of technology varied. Faculty and staff identified the term student success as a student successfully navigating campus, retention to the next semester, graduation from the institution, career readiness, changing majors, overcoming obstacles, and/or transferring institutions. Faculty and staff perceived student success to be a campus term for retention and graduation initiatives. Academic advisors and members of academic support offices who did not have it specifically in 
their job duties reported student success as other duties as assigned or a good faith effort. Faculty also shared that it was a good faith effort to participate. Faculty and staff had connected early alert as a student success practice; however, there was a disconnect to understanding how their role in student success connected to the technology and functional elements that early alert supports. For example, faculty at S\&T did not understand why they should raise a flag or in some cases give timely feedback. Through focus group, discussion advisors were able to share how they integrate information to outreach and holistic see information to support student success.

Furthermore, depending on the office at each campus, many users shared that use of the early alert system was not formally integrated into their job. For example, MU and UMSL both have a Retention Office and early alert has been defined as a core process to support students in that office. However, flag responders in other academic support functions (e.g., academic advising) varied throughout each campus. This was common across all campuses, where some units widely adopted the tools while other offices did not fully embrace the tools in an ongoing way. Many users expressed that it was another "thing" to add to their plates when they felt that their tasks were overloaded as it was.

Human Resource Expectations \& Staffing. Findings pointed to the need for additional staffing to support each campuses early alert process. Human resource support and evaluation at both the system and campus level are needed for key contributing roles of those involved in the early alert process. The hiring of leadership member at the system level to support and assess effectiveness at each campus should be present. In addition, at least one staff member and/or additional staff to support tool development, implementation, training and onboarding needs be 
present each campus in a full-time capacity to be considered to grow adoption and sustain the growth needed to effectivity support early alert.

Oftentimes, organizational technology can fail because it requires that some people may have to do additional work and those people are not the ones who understand the direct benefit from the technology (Grudin, 1988). Identification and communication of an office and person(s) responsible are key to effective implementation and coordination of the system (Greenfield et al., 2013). During implementation, each campus assigned a support person to implementation. MU hired a new full time staff where at UMSL, UMKC, and S\&T assigned the project to a current staff members at the central campus level to support implementation. UMKC and S\&T hired a full time staff after initial implementation. Leadership expressed a need for more resources to support the ongoing work. In addition, academic advisors expressed a need for more support of early alert outreach process. They shared that due to capacity of their current advising loads it was difficult to integrate into their current advising roles.

Training. Training is an essential function that should be integrated for all users who are core to the early alert processes (i.e., Faculty, Academic Advisors, Financial Aid Advisors, Residential Life Staff, Academic Support Staff)(Greenfield et al., 2013). Workshops should be made available at times where it is convenient for staff and faculty to participate. A training plan should be incorporated into implementation and ongoing planning. Workshops should also be integrated into campus events to onboard or to scale user adoption. Events include: new faculty orientation, departmental meetings, retreats, advisor trainings, and staff meetings.

\section{Technology}

Participants at each campus expressed that they were often overwhelmed with the amount of early tools that they had access to and were unsure what they were supposed to do with the 
information. One person, for example, asked "is it informational or is it something I should act on?" Users shared that they were "afraid they would hit the wrong button, and that they didn't know what flags were systematic versus manual." While this was said at all campuses, this was discussed most at UMKC, due to this campus having a large number of system and manual flags in place, thus confusing users on the processes. In addition, users at UMKC shared that the technology was not giving them the whole picture of the student information because it's held down between divisions rather than creating holistic access to those with an academic need to know. UMKC's system design should be reviewed to better equip academic advisors with the capabilities that the system was aimed to support. Lastly, all campuses were overwhelmed with the amount of technology being introduced at the faculty and staff levels. This was expressed the most at MU, with staff sharing the need for more integration of technology, training, and communication.

\section{Data \& Assessment}

How do we know if it works? This is the ongoing question posed by all campuses. Users expressed a need to be more data informed and shared that data would be a large influence to buy in for both faculty and staff. An assessment plan needs to be created at the UM System and at each campus. The plan should include operational and outcome data, and also be incorporated into the overall implementation planning process (Greenfield et al., 2013). Assessment should also draw from both quantitative and qualitative data. Examples include student, staff, and faculty focus groups, implementation surveys, operational data to show participation, and formative evaluations regarding satisfaction with the technology. Outcome data should also be assessed. Common questions to pose include: What offices are engaging and what offices need further support? What students should be targeted? What outreach processes are most effective? 
What improvements can be made to current outreach processes? Where should be operationalize new tactics to support student success? What factors demonstrate a positive outcome for students and courses? Do students who participate have a change in academic performance? Is there a relationship between attendance and retention? Not only will the data collection impact implementation but also it will influence those tasked to use the tools to keep engaging in early alert processes and engage new users.

\section{Conclusion}

Early alert programs and technology systems are a new and evolving practice at large 4year public institutions. The organizational structure, perception of student success, and intersection of technology, people, task, and structure are key areas to understand in order to advance conversations regarding implementation and user adoption of early alert systems. The conceptual framework of social-technical theory provides the first steps to understand the relationship between people and technology. This framework further evolves into a later sociotechnical model of Leavitt's (1964) Integrated Approach to Change Framework provides a way to understand the complex interrelationships to further explore the technology adoption challenge at each UM System campus. In addition, early alert systems provide an accountability measure to demonstrating student outcomes to provide additional funding to intuitions to reinvest in student success efforts. The interdependent relationship between people, structure, tasks, and technology are critical components to research and provide implications for practice to aid administrators in implementation and adoption planning to address early alert programming to support student success initiatives at 4-year public institutions. 
Figure 1. Leavitt's (1964) Diamond, An Integrated Approach to Change

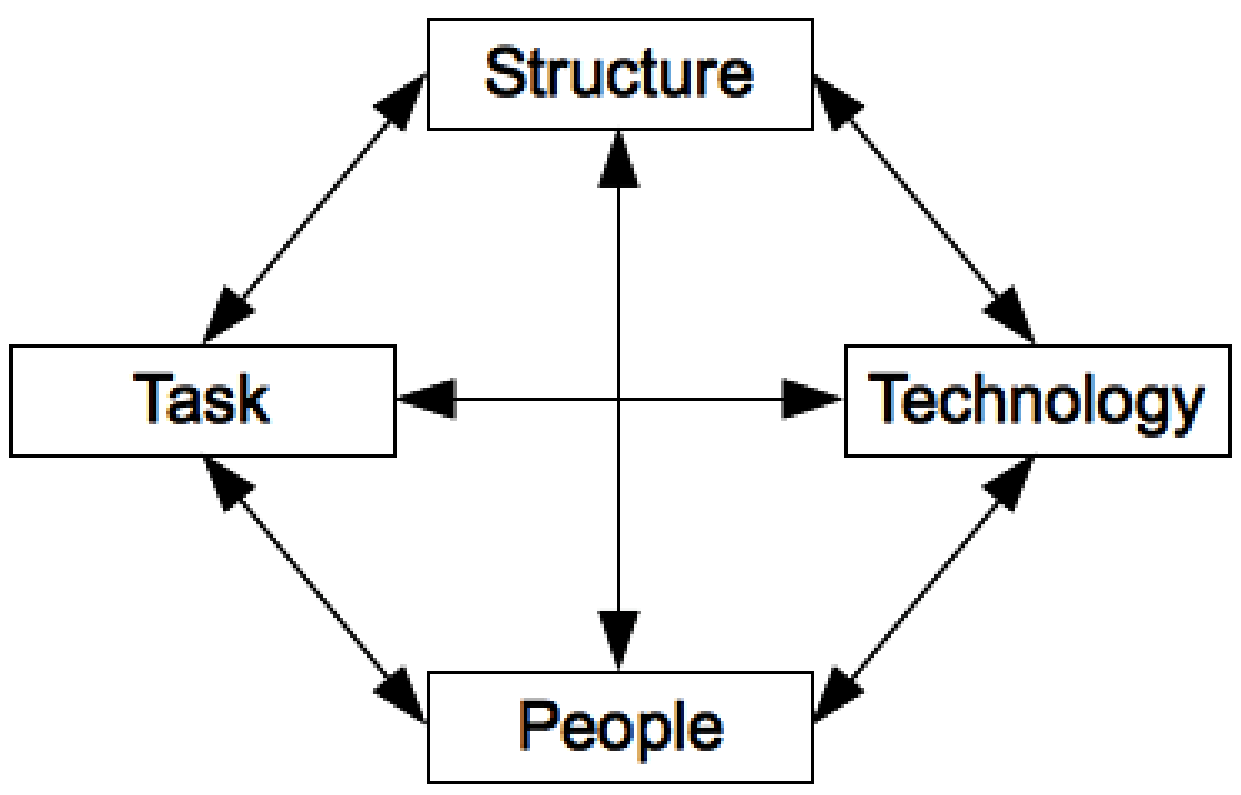


Figure 2. Research Contribution to Practice--Leavitt's Diamond, Modified

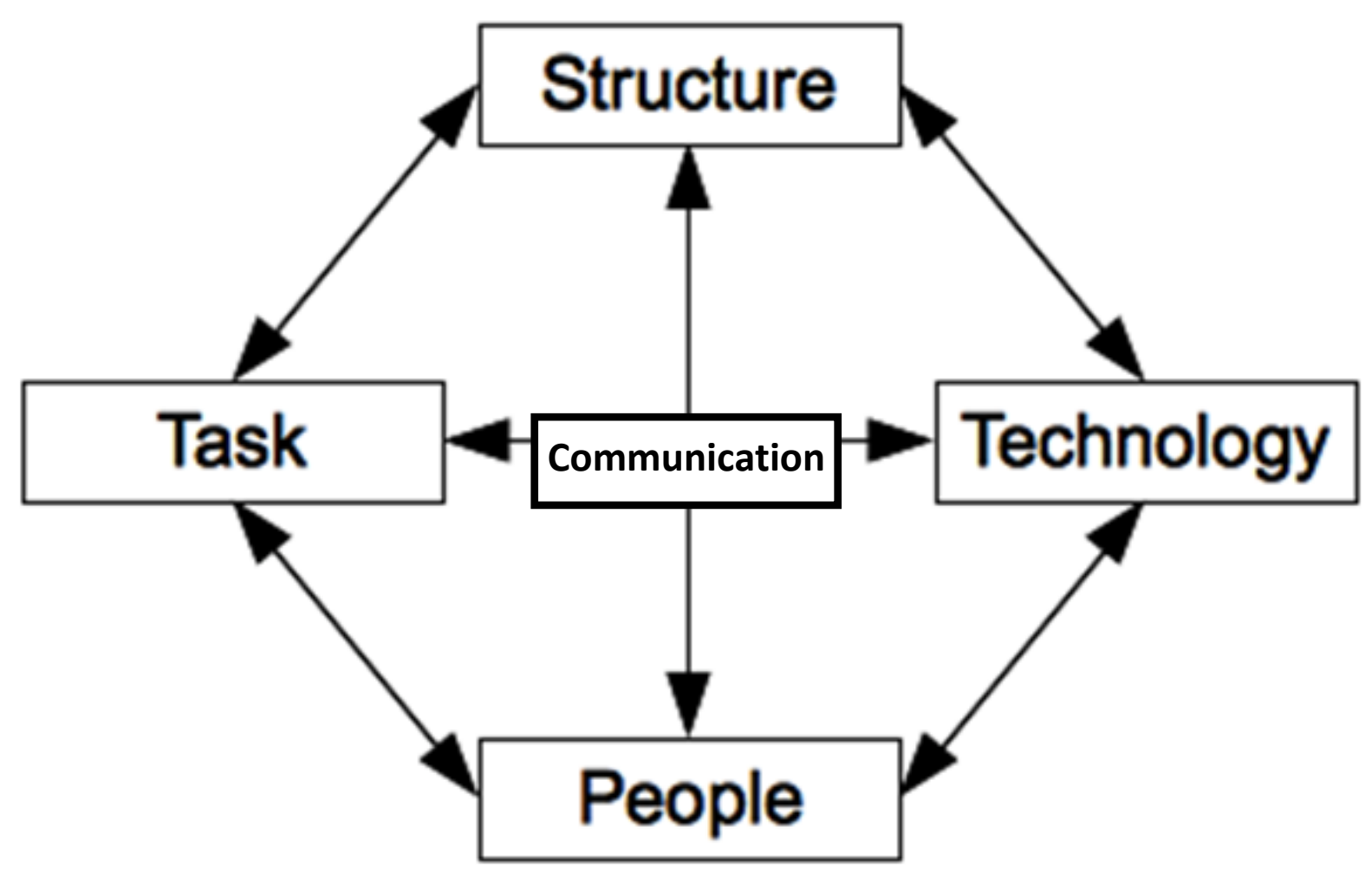




\section{SECTION SIX:}

\section{SCHOLARLY PRACTITIONER REFLECTION}

\section{Dissertation Influencing Education Leadership}

There have been several changes to my leadership during my exploration in coursework. "What we see depends on what we are prepared to see" Senge (as cited in Shafrtiz et al. 1990/2005, p. 443). This quote describes my transformation in the EdD program. Using what I have learned has made me more prepared to "see" things differently. This starts with reflection and asking myself thoughtful questions regarding how I view the world through my mental model. This has impacted my approach in problem solving and using data to inform decision making and my awareness of equity to make decisions that are equitable for all parties involved. In addition, I have a new viewpoint as being a leader as an educator. As an educator, I am also in a position to create change.

\section{Leadership Theory}

Bolman and Deal (2008) discussed that organizations are complex, surprising, deceptive, and ambiguous. Navigating the organizational landscape takes good leadership and because of this leadership also needs to be flexible. In my coursework, there were two leadership styles that resonated with me the most: situational leadership and skills approach to leadership. Bolman and Deal (2008) discussed good leadership is understanding that what works in one setting will not work in another. The leadership style most applicable to this understanding is situational leadership. Situational leadership is the ability to recognize what others need and then adapt the leadership approach to meet their needs (Northouse, 2013). As a leader, I find myself never tackling similar situations with the same approach. Each situation calls for an open mind when approaching a problem. It is important to treat each problem as its own issue because it comes 
with differing needs, people, situations, and policy implications. Having flexibility in my approach allows me to pivot in different ways to achieve the best possible outcome. Leadership approaches in this context cannot be prescriptive, and must use both directive and supportive behaviors described by Northouse (2013). Directive behaviors include sharing the big picture with others to accomplish goals by giving direction, parameters, and a time line for completion. The supportive behavior is a compliment and is the relationship building aspect that helps other feel comfortable with what the directive behavior is asking of them (Northouse, 2013). As I am giving direction to teams I have found that use both directive and supportive behaviors and share the big picture and future direction, to help others feel good about what is about to take place.

The second leadership style that resonated with me is the skills leadership approach. The skills approach described by Northouse (2013) discussed how personality characteristics play a role in leadership and how this approach utilizes knowledge and abilities to be an effective leader. For the leader to have conceptual skills it depends on the leaders' ability to solve complex organizational problems. This approach to leadership is different from many leadership styles because these skills can be acquired through experience rather than personal characteristics of the leader (Northouse, 2013). Northouse (2013) discussed three elements that define the skills approach; technical, human, and conceptual skills. The technical skill is having the knowledge or skills in a particular area. The human skill involves the ability to work with people and navigate a team to achieve a common goal (Levi, 2013; Northouse, 2013). The last trait of conceptual skill gives a leader the ability to work with ideas. Overall, the skills approach resonates with me as a leader because of the problem solving skills needed to work with things (technical), people (human), and ideas (conceptual). Acquiring skills is important to leadership 
because as my skills become concrete to apply to practice I can continue to improve and develop overtime rather than relying on inherent traits.

The skills approach to leadership and situational leadership have similarities of navigating the human element of guiding people by understanding the underpinnings of ideas rooted by policy, and the importance for the leader to change their style to meet the needs of others. Both models give insight as to how I lead best and gives meaning to my natural abilities and personal development. Understanding these concepts makes me a better leader because it has helped me to create an awareness about the organization, people, and policy that leads me to effectively navigate and solve problems to create positive change.

\section{My Mental Model}

During coursework and in my professional practice transformational learning took place and that increased by awareness of my own schemas. For the purpose of this section, I will refer to schemas as a mental model as described in coursework. Brookfield (as cited in Mezirow, 2000/2006) discussed that not critically reflecting upon and examining of my own metal model may be detrimental to leadership influence. Without examination of my own thoughts, I would be limited in how I view the world and how I respond to action because my personal mental model shapes how I approach and make decisions. My mental model is my own experiences, data, meanings, assumptions, conclusions and beliefs and all of those together shape if I act or chose not to act (Mezirow, 2006). As a leader, it is important to have continued reflection so I am aware of my thoughts and feelings and can easily respond to work situations because of my own personal awareness. 


\section{Equitable Problem Solving and Decision Making}

In my nine years of experience at MU, I found that many faculty and staff members have become engrained in the way they serve students. I have witnessed that as the students change each year, faculty and staff practices are slow to change. This becomes a problem because people are grounded in their practices and it became very apparent that it was going to be difficult to deinstitutionalize their way of thinking to adopt a new technology (Larson \& Ovando, 2001). Meaning to remove the cultural barrier and stop the cycle of "this is the way we have always done things here." Trying to change their way of thinking is no small task.

When offering new approaches to support and enhance the work that they are doing through technology, I have experienced the resistance. On occasions where I was able to take the risk to ask why and challenge the status quo I heard things such as "I've done it this way for years," "Why should have to do this?," "I am a creature of habit," "I am unsure if this will work," "This is going to create more work for me." Those who have been working on campus for a long time produce habits that do not require decisions to be made and those actions form a habit that gets passed onto generations of new staff and will result in groupthink (Larson \& Ovando, 2001; Levi, 2013).

Larson and Ovando (2001) discussed institutionalized inequity and this something that has changed my leadership practices because it has changed my decisions making process to recognize how my decisions could be inequitable for others involved. When working with technology I have to assess all parties involved and make sure that equitable approaches are taken into account to support all parties involved. Knowing that faculty and staff are a mix of technology natives and immigrants it is important to recognize that users have various levels of navigational skills, technology literacy, and training. I strive to make technology accessible, 
provide trainings and recognize the needs of others, recognize the navigational roadblocks, and communicate as much as I can to support all involved.

As a result of identifying these patterns, I am more aware of diversity, viewing problems from different perspectives, using reliable data, and be open minded to widen my frame of reference (Kahneman, Lovallo, \& Sibony, 2011/2013). In addition, I also took time to better understand student needs by conducting focus groups, working with student life, and conducting surveys to make sure the student voice was heard before making decisions. Additionally, knowing that diverse student interactions with resources may be limit student learning experience at predominately White campuses the technology was even more important to support our diverse students at MU (Hurtado, Milem, Clayton-Pedersen, \& Allen, 1998). This has been very useful when making equitable decisions and assessing areas of diversity and how technology can influence student success on campus for at risk students.

\section{Educator as a Leader}

One of the changes that has resulted from my EdD experience is understanding the role that I have to educate others as a way of leading. Learning at the individual level happens when a person learns new knowledge, skills, attitudes and beliefs that changes the way the person looks at the world, conducts work, and contributes to the organization (Gill, 2009; Merriam \& Bierema, 2013). One of the ways that I influence adult learning at an individual level is through trainings and workshops with advisors, faculty, and student services coordinators on campus. Adult learners' motivation to learn is much higher if an adult leader can see the importance before they begin (Merriam \& Bierema, 2013). Applying adult learning literature to practice has been impactful because it delivers communications in different ways to emphasize the importance of the technology on our campus before and after training to create a continuous 
learning culture (Gill, 2009). A change as a result of my coursework experience was adopting a “Teaching Around the Circle Approach" to apply to various learning styles (Merriam \& Bierema, 2013). I have utilized active experimentation approaches to include creating actions plans and problem-solving. In addition, I have also adopted concrete experience approaches to have others recall past experiences, demonstration, and observation. I have also created quick reference guides, charts, and other documents related to training that reinforce abstract

conceptualization. Lastly, I have also included reflective observation that includes small group discussion during trainings and workshops to facilitate conversation and reflection with peers (Merriam \& Bierema, 2013). My coursework changed my leadership approach because I now recognize various learning styles to be aware of and cater to during trainings by using different mechanisms to help information appeal to adult learners learning styles.

\section{Leader as a Change Agent}

In order to grow as a change agent on campus I need to change my way of thinking to better understand cultures to navigate the institution to promote change in a positive way. The systems thinking approach discussed by Senge (as cited in Shafritz et al., 1990/2005) discussed seeing inter relationships rather than things. Seeing process of change rather than snapshots was critical in my role because I needed to understand the student success process each area added and how they fit into the whole institution. In my leadership role on campus it is also my responsibility to constantly align the processes around policy and apply it using technologies. Systems thinking helped me to gain a deeper understanding of patterns that lies behind each areas motivation to use the technology and benefits for the students.

While I have positioned myself as a change agent on campus to include many facets of leadership, policy, and the organization. However, I have also recognized that the right kind of 
culture will influence how effective organizations are (Bolman \& Deal, 2008; Levi, 2013). In turn, my responses to various questions and my approach also can cause success or failure of the project. An area that has allowed me to grow as a change agent is being faced with ethical dilemmas. I recognize if I do not encourage a process of open inquiry it brings into question the ethical nature of my leadership (Mihelic, Lipicnik, \& Tekavcic, 2010). Early Alert is not a new concept however, there have been several faculty and staff members that are apprehensive because they feel like the system is big brothering students. These are tough conversations and I often start with appreciative inquiry by asking those who ask me tough questions to tell me more, ask them what about this is important to them, what they feel like the possibilities are, and how we can support them (Kotter, 1996). By asking deeper questions provides more feedback with the change management process rather than just telling people why they should participate.

Ettling's (2012) article talks about the educator as a change agent by sharing experiences, unveiling conflict, and evoking the unconsciousness. As a change agent, I share my own experiences and others experience through storytelling to advance the adoption on new technologies and new practices. I also create a safe learning environment so adult learners can safely be challenged to their learning edge to draw in conversations to advance practices. Lastly, I am change agent that removes barriers to learning and in order to facilitate learning I must take risks, engage in action learning, continuous feedback, and reflection (Gill, 2009). By approaching change in an intentional way, understanding the ethical dilemmas for new users, and the culture that is influencing user's beliefs and values aids me to respond in a way that finds common ground to influence change at MU. 


\section{Dissertation Influencing Scholarship}

The dissertation process has been a journey. The process, networking, and next steps are all areas that I think about when I reflect on how it has influenced my scholarship. When I think about where I was in the planning stages, proposal, data collection, analytics, and implication for practice stages of my research I think about how much of a marathon it has been. For me I just did not want to go through the motions I wanted to contribute something that was innovative, ground breaking, and be used an applied by higher education leaders and companies. I set high expectations for myself and the work that I wanted to do. I heard so many say to me just get it done and move on. I was told by some that this should be the "worst" thing I ever write because it was my first. As I begin to think more about it, I wanted it to be the best because I was going to do something that was timely and relevant in the higher education field today.

The dissertation processes challenged me to network with my peers and campuses where I collected my research. I also reached out to scholars around the framework that I used and was eager to learn more about how we can incorporate social-technical systems into higher education. It was more than research and documenting findings, it was a journey to uncover the answers to my questions and add value to student success practice. Moving forward I have a body of work with several strong arguments to publish papers and present at conference. In addition, it will be best applied to those at the University of Missouri to network with leadership to advance the work that they are already doing.

Starting my proposal and then looking at where I am now, I have learned that this is just the start. While I am well versed in this one area, I now have many more questions than I did when I first started my research. I was only able to tackle a few questions and make great connections to my findings, but I recognize that there is more that can be done in the future. 


\section{Conclusion}

The EdD program has positivity influenced my application to practice of leadership theory, organizational analysis, and policy implications and that directly impact my leadership development. The dissertation process has influenced my writing and frame in which I approach research and application to practice. The positive changes that I have made have been a constant evolution of myself coupled with rich in class experiences, applied literature practices, and a strong peer supported network. I am a scholarly-practitioner and I can now serve the campus community in a higher capacity because of the knowledge and skills gained from coursework and my dissertation process. I am more confident in making decisions because of my increased awareness and application to practice. I have made and will continue to make decisions that can be directly linked back to scholarly literature and practice. While leadership development is an ongoing process the contributions that the EdD program has made along with my dedication to coursework has produced a positive change in my leadership and skill development. 


\section{References}

Ackerman, M., Prilla, M., Stary, C., Herrmann, T., \& Goggins, S. (2017). Designing healthcare that works: A sociotechnical approach. Academic Press.

Adams, R. H., \& Ivanov, I. I. (2015). Using Socio-Technical System Methodology to Analyze Emerging Information Technology Implementation in the Higher Education Settings. International Journal of e-Education, e-Business, e-Management and e-Learning, 5(1), 31.

Appelbaum, S. H. (1997). Socio-technical systems theory: an intervention strategy for organizational development. Management Decision, 35(6), 452-463.

Barefoot, B. O. (2004). Higher education's revolving door: Confronting the problem of student drop out in US colleges and universities. Open Learning: The Journal of Open, Distance and e-Learning, 19(1), 9-18.

Bean, J. P. (1990). The strategic management of college enrollments. San Francisco: CA Jossey Bass.

Bolman, L. G., \& Deal, T. E. (2008). Reframing organizations: Artistry, choice and leadership. (4th ed.). San Francisco, CA: Jossey-Bass.

Bolman, L. G., \& Gallos, J. V. (2011). Leading from the middle. Reframing academic leadership San Francisco, CA: Jossey-Bass. 143-162.

Cherns, A. (1976). The principles of sociotechnical design. Human Relations, 29(8), 783-792.

Clarke, K. (2006). Trust in technology: A socio-technical perspective (Vol. 36). springer Science\& Business Media.

Creswell, J. W. (2013). Research design: Qualitative, quantitative, and mixed methods approaches. Thousand Oaks, CA: Sage publications. 
Cuseo, J. (2006). At-Risk Prediction Instruments, Early-Alert Systems \& Exit Interviews: A Proactive-to-Reactive Continuum of Efforts to Promote Student Success. Retrived from https://pdfs.semanticscholar.org/16af/f131fe66eceb9089a47837da7a790db0dba7.pdf

Dalton, D. R., Todor, W. D., Spendolini, M. J., Fielding, G. J., \& Porter, L. W. (1980). Organization structure and performance: A critical review. Academy of Management Review, 5(1), 49-64.

Drake, P., \& Heath, L. (2011). Thinking about ethical considerations. Practitioner research at doctoral level. New York, NY: Routledge.

Emerson, R. M., Fretz, R. I., \& Shaw, L. L. (2011). Writing ethnographic fieldnotes (2nd ed.). Chicago, IL: University of Chicago Press.

Greenfield, G. M., Keup, J. R., \& Gardner, J. N. (2013). Developing and sustaining successful first-year programs: A guide for practitioners. John Wiley \& Sons.

Grudin, J. (1988). Why CSCW applications fail: problems in the design and evaluation of organizational interfaces. In Proceedings of the 1988 ACM Conference on Computer Supported Cooperative Work (pp. 85-93). ACM.

Karp, M. J. M., \& Fletcher, J. (2014). Adopting new technologies for student success: A readiness framework. Community College Research Center. Columbia University.

Kemmis, S., \& Wilkinson, M. (1998). Participatory action research and the study of practice. Action research in practice: Partnerships for social justice in education, 1, 21-36.

Kuh, G. D., Kinzie, J. L., Buckley, J. A., Bridges, B. K., \& Hayek, J. C. (2006). What matters to student success: A review of the literature (Vol. 8). Washington, DC: National Postsecondary Education Cooperative.

Leavitt, H. J. (1964). Applied organisation change in industry: structural, technical and human 
approaches. New perspectives in organization research. New York: Wiley.

Merriam, S. B., \& Bierema, L. L. (2013). Adult learning: Linking theory and practice. John Wiley \& Sons.

Merriam, S. B. (2009). Qualitative research: A guide to design and implementation. Hoboken, NJ: Jossey-Bass.

Mintzberg, H. (1980). Structure in 5's: A synthesis of the research on organization design. Management Science, 26(3), 322-341.

Missouri Department of Higher Education, Coordinating Board for Higher Education. (2012). Performance funding model: Recommendations of the performance funding task force. Retrieved from http://dhe.mo.gov/documents/PerformanceFundingReport.pdf

Missouri Science and Technology. (n.d.). History of Missouri Science and Technology. Retrieved from http://chancellor.mst.edu/history/

Missouri Science and Technology. (n.d.). $S \& T$ mission statement. Retrieved from http://chancellor.mst.edu/mission/

Missouri Science and Technology. (2017). Enrollment reports. Retrieved from http://registrar.mst.edu/media/administrative/registrar/documents/enrollment/fs17grid.pdf

Missouri Science and Technology. (2016). S\&T organizational chart. Retrieved from http://ira.mst.edu/media/research/ira/documents/organizationalcharts/Website\%20Versio n\%20September\%202014.pdf

MO SB492, Regular Session, (2014, January 28).

Murtaugh, P. A., Burns, L. D., \& Schuster, J. (1999). Predicting the retention of university students. Research in Higher Education, 40(3), 355-371.

Pasquini, L.A.,\& Evangelopoulos, N. J. (2017).Computing in Higher Education 29 (218). 
https://doi.org/10.1007/s12528-016-9130-0

Pritchard, I. A. (2002). Travelers and trolls: Practitioner research and institutional review boards. Educational Researcher, 31(3), 3-13.

Simons, J. M. (2011). A national study of student early alert models at four-year institutions of higher education (Doctoral dissertation). Retrieved from ProQuest.

Stake, R. E. (1995). The art of case study research. Thousand Oaks, CA: Sage.

Tampke, D. R. (2012). Developing, implementing, and assessing an early alert system. Journal of College Student Retention: Research, Theory and Practice, 14(4), 523-532.

Tampke, D. R. (2009, September). Developing and Implementing an Early Alert System. In National Symposium on Student Retention (p. 143).

Tinto, V. (1975). Dropout from higher education: A theoretical synthesis of recent research. Review of Educational Research, 45(1); 89-125.

University of Missouri. (2016a). History and traditions. Retrieved from http://missouri.edu/about/history/index.php/

University of Missouri. (2016b). Organizational charts. Retrieved from http://ir.missouri.edu/organization/index.html

University of Missouri. (2017). MU facts. Retrieved from http://missouri.edu/about/facts.php/

University of Missouri-Kansas City. (2016a). Student facts. Retrieved from http://www.umkc.edu/facts/\#student

University of Missouri-Kansas City. (2016b). UMKC organizational chart. Retrieved from http://www.umkc.edu/chancellor/documents/umkc-org-chart.pdf

University of Missouri-St. Louis. (2016a). UMSL By the Numbers. 
Retrieved from https://www.umsl.edu/proud/by-the-numbers.html University of Missouri-St. Louis. (2016b). UMSL organizational chart. Retrieved from http://www.umsl.edu/ mts/telephone-directory/organizational_chart.pdf

University of Missouri System. (2016). History of UM System. Retrieved from https://www.umsystem.edu/ums/about/history/

Varney, R. A. (2008). Study of early alert intervention on first-year, nondevelopmental community college freshmen. ProQuest.

Yin, R. K. (2009). Case study research: Design and methods. Essential guide to qualitative methods in organizational research. In The Information Systems Research Challenge. 5(1). London: Sage. 


\section{Appendix A}

\section{Recruitment Email to Participate in Research Study}

\section{$<$ Date>}

\section{Dear}

My name is Tina Balser and I am the Starfish administrator at the University of Missouri. I am also a doctoral student in the Educational Leadership and Policy Analysis EdD program at the University of Missouri- Columbia. I am writing to ask for your participation in a research study concerning Implementation of Early Alert Systems at four year public institutions.

The purpose of this study is to understand the relationship between leadership, users (faculty and staff), technology, and the organization when implementing a campus wide early alert program facilitated by new technology. This will provide administrators and practitioners with strategic approaches to tackle future early alert implementation and adoption challenges at four-year public universities. Conducting this research will provide further resources and implications to assist the institutions in this study and future institutions who are looking to engage in this work. In addition, this study will add to the lack of literature of early alert system implementation at four-year public institutions and aid campus leadership with future decision-making.

I am inviting your to participate in an (Interview/Focus Group) during (Month/Day/Year Timeframe) at (Institution Name) in (Location). Please respond back to me by (Date) to confirm your interest in participating in the study. Please contact me at balsert@ missouri.edu or 573-8845720 with any questions. I look forward to hearing from you.

Kind Regards,

Tina Balser

Principal Investigator

Educational Leadership and Policy Analysis Doctoral Candidate

(573) 884-5720

Balsert@missouri.edu 


\section{Appendix B}

\section{Consent Form to Participate in a Research Study}

Researcher's Name(s): Tina Balser

Project Number: \#2005307

Project Title: A Multisite Case Study of Early Alert Implementation at the University of Missouri System

The purpose of this study is to understand the dynamics involved when implementing a campus wide early alert program using new technology. This will provide administrators and practitioners with strategic approaches to tackle future early alert implementation and adoption challenges at four-year public universities. Conducting this research will provide further resources and implications to assist the institutions in this study and future institutions who are looking to engage in this work. In addition, this study will add to the lack of literature of early alert system implementation at four-year public institutions and aid campus leadership with future decision-making. Your participation is voluntary. You do not have to be in the study if you do not want to. If you do participate and later decide that you do not want to continue to be in the study, you may stop at any time without penalty.

HOW MANY PEOPLE WILL BE IN THE STUDY?

About 40 people across 4 campuses will be invited to take part in this study.

\section{WHAT AM I BEING ASKED TO DO?}

You will be asked to participate and give your honest feedback as a staff member at the University of Missouri System . The interview that you will participate in will last for 30-60 minutes. The information that you will be asked for will be questions regarding your experience leading, implementing, and/or participating in a new campus wide early alert system. You also have the option of not participating in this study, and will not be penalized for your decision.

\section{CONFIDENTIALITY}

Information produced by this study will be stored in the researcher's file and identified by a code number only. The code key connecting your name to specific information about you will be kept in a separate, secure location. Information contained in your records may not be given to anyone unaffiliated with the study in a form that could identify you without your written consent, except as required by law.

\section{WHAT ARE MY RIGHTS AS A PARTICIPANT?}

Participation in this study is voluntary. You do not have to participate in this study. Please contact Tina Balser, balsert@missouri.edu if you have questions about the research. Additionally, you may contact Dr. Casandra Harper at harpercas@ missouri.edu or 573-882-2818.

If you have any questions regarding your rights as a participant in this research and/or concerns about the study you may contact the University of Missouri Campus Institutional Review Board at (573) 882-9585 or umcresearchcirb@missouri.edu.

A copy of this Informed Consent form will be given to you before you participate in the research. 


\section{Appendix C}

\section{Interview Questions}

1. What is your role with the early alert implementation?

2. What was the catalyst for your early alert implementation?

3. Tell me about your early alert implementation.

4. Who manages the various parts of the system?

5. How does the UM System Initiative play a role in using the new technology?

6. Does your campus encourage co-operation and collaboration with the technology?

7. Was there a timely attempt made to prepare people for the changes?

8. When did early alert implementation start?

9. What was your approach?

10. Did you observe others have resistance to using a new technology?

11. What stakeholders where critical in your implementation efforts?

12. What offices were a part of our initial implementation, why?

13. What student's populations are targeted with early alert tools?

14. How were students made aware of the new technology?

15. What was successful?

16. What are the biggest obstacles, sources of conflict?

17. How do you measure success?

18. What additional comments would you like to share? 


\section{Appendix D}

\section{Focus Group Questions}

Card filled out at beginning of focus group. (Name, Role, Role in Early Alert, Student Populations Targeted)

1. What does student success mean to you?

2. Describe your ideal early alert program/process?

3. Of what you described, what pieces do you have in place here? Why?

4. Of what you described, what pieces don't you have in place? Why?

5. Share about your early alert implementation

6. How did you learn about using your campuses' Early Alert technology?

7. How were you introduced to it?

8. Are you required to use it?

9. What factors with in your day to day work help or hinder your use of the technology?

10. How have you adapted or not adapted to the technology?

11. Did you feel resistance to using new technology?

12. What mechanisms did you use before having technology?

13. Now that you have technology to facilitate early alert on your campus, how often do you use it? Why?

14. Do you feel that the EA tools are effective to help students be successful? Why or why not?

15. From your perspective what has been the biggest success?

16. From your perspective what has been the biggest challenge?

17 . What additional comments would you like to share? 


\section{VITA}

Tina Balser, Director of Student Success Initiatives, she has worked at the University of Missouri in Columbia, Missouri for 9 years. Currently, she leads implementation, management, and assessment of student success technologies (Starfish and PAR). She provides training and support for users, and works extensively with academic schools and colleges, faculty, and campus student support services to align technologies with campus student success initiatives. Tina holds a BSBA in Business Administration from the University of Central Missouri, a M.Ed. from the University of Missouri in Higher Education Administration and is pursuing her EdD as a doctoral candidate in Educational Leadership and Policy Analysis at the University of Missouri. Tina is from Rockford, Illinois and married to Nick Balser and the mother of Isabella and Maxwell Balser. 